ICTD Working Paper 130

\section{Assessing the Equity and Redistributive Effects of Taxation Reforms in Nigeria}

Henry C. Edeh

November 2021 
Assessing the Equity and Redistributive Effects of Taxation Reforms in Nigeria

Henry C. Edeh

ICTD Working Paper 130

First published by the Institute of Development Studies in November 2021

(C) Institute of Development Studies 2021

ISBN: [978-1-78118-867-5]

DOI: $10.19088 /$ ICTD.2021.020

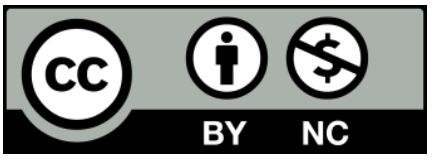

This is an Open Access paper distributed under the terms of the Creative Commons Attribution Non Commercial 4.0 International license, which permits downloading and sharing provided the original authors and source are credited - but the work is not used for commercial purposes. http://creativecommons.org/licenses/by-nc/4.0/legalcode

\section{Available from:}

The International Centre for Tax and Development at the Institute of Development Studies, Brighton BN1 9RE, UK Tel: +44 (0) 1273606261

Email: info@ictd.ac

Web: www.ictd.ac/publication

Twitter: @ICTDTax

Facebook: www.facebook.com/ICTDtax

IDS is a charitable company limited by guarantee and registered in England

Charity Registration Number 306371

Charitable Company Number 877338 


\title{
Assessing the Equity and Redistributive Effects of Taxation Reforms in Nigeria
}

\author{
Henry C. Edeh
}

\begin{abstract}
Summary
Achieving the Sustainable Development Goals (SDGs) of poverty and inequality reduction through redistribution have indeed become critical concerns in many low- and middle-income countries, including Nigeria. Although redistribution results from the effect of tax revenue collections, micro household-level empirical analyses of the distributional effect of personal income tax (PIT) and value added tax (VAT) reforms in Nigeria have been scarcely carried out. This study for the first time quantitatively assessed both the equity and redistributive effects of PIT and VAT across different reform scenarios in Nigeria. Data used in this study was mainly drawn from the most recent large scale nationally representative Nigeria Living Standard Survey, conducted in 2018/2019. The Kakwani Index was used to calculate and compare the progressivity of PIT and VAT reforms. A simple static micro-simulation model was employed in assessing the redistributive effect of PIT and VAT reforms in the country. After informality has been accounted for, the PIT was found to be progressive in the pre2011 tax scheme, but turned regressive in the post-2011 tax scheme. It was also discovered that the newly introduced lump sum relief allowance in the post-2011 PIT scheme accrues more to the high-income than to the low-income taxpayers - confirming the regressivity of the current PIT scheme. However, the study further shows (through counterfactual simulations) that excluding the relatively high-income taxpayers from sharing in the variable part of the lump sum relief allowance makes PIT progressive in the post-2011 scheme. The VAT was uncovered to be regressive both in the pre-2020 scheme, and in the current VAT reform scheme. Further, after putting informality into consideration, the PIT was found to marginally reduce inequality but increase poverty in the pre-2011 scheme. The post-2011 PIT scheme reduced inequality and increased poverty, but by a smaller proportion confirming a limited redistribution mainly resulting from the concentration of the lump sum relief allowance at the top of the distribution. However, if the variable part of the lump sum relief allowance is provided for 'only' the low-income taxpayers below a predefined income threshold, the post-2011 PIT scheme becomes largely redistributive. VAT was uncovered to marginally increase inequality and poverty in the pre-2020 scheme. Though the current VAT scheme slightly increased inequality, it considerably increased poverty in the country. It is therefore suggested that a better tax reform, with well-regulated relief allowance and differentiated VAT rates, will help to enhance the equity and redistribution capacity of the Nigeria tax system.
\end{abstract}

Keywords: equity, redistribution, income tax, value added tax, lump sum relief allowance.

Henry Edeh is a Postgraduate Researcher at the Department of Economics, University of Nigeria. 


\section{Contents}

Summary 3

$\begin{array}{ll}\text { Acknowledgements } & 6\end{array}$

$\begin{array}{ll}\text { Acronyms } & 6\end{array}$

$\begin{array}{ll}\text { Introduction } & \mathbf{7}\end{array}$

$1 \quad$ Literature review 11

$2 \quad$ Structure of tax revenue in Nigeria 13

2.1 Key insights to the 2011 PIT Act, relative to the old PIT Act 14

$3 \quad$ Research objectives $\quad 15$

$4 \quad$ Data and methods $\quad 15$

4.1 Data sources 15

$\begin{array}{lll}4.2 & \text { Variables calculations } & 16\end{array}$

$\begin{array}{lll}4.3 & \text { Accounting for informality in PIT and VAT } & 17\end{array}$

$\begin{array}{lll}\text { 4.4 Method to assess the progressivity of PIT and VAT } & 17\end{array}$

4.5 Method to assess the redistributive effect of PIT and VAT 18

4.6 Micro-simulation of the relief allowance structure in the 2011 PIT Act 21 4.6.1 Defining eligibility criterion for lump sum relief allowance distribution across individual households in the middle/low-income category 22

5

\section{Results}

5.1 Economic activities and earnings of the average Nigerian household 23

5.2 Equity and redistribution analyses of taxation reforms 24

$\begin{array}{lll}6 & \text { Discussion and conclusion } & 38\end{array}$

$\begin{array}{ll}\text { References } & 41\end{array}$

$\begin{array}{ll}\text { Appendix } & 47\end{array}$

Tables

Table 1

Table 2

Table 3

Table 4

Table 5

Table 6

Table 7

Table 8

Table 9

Table 10

Table 11

Table 12

Table 13

Table 14

Table 15
Structure of tax revenue in Nigeria, 2018

Household economic activities, together with corresponding average income shares

23

Progressivity of PIT under each scenario

Simulating progressivity of the post-2011 PIT relief structure

Progressivity of VAT under each scenario

25

27

28

Estimated effects of PIT under each scenario with respect to the base scenario

Estimated effects of VAT under each scenario with respect to the base scenario

Pre-2011 income tax structure in Nigeria, 1993/1998 laws 47

Post-2011 income tax structure in Nigeria, 2011 to date 47

Description of the simulation scenarios for the redistributive effect of PIT 47

Description of the simulation scenarios for the redistributive effect of VAT 47

Confidence intervals of average incomes of Nigeria households 48

Confidence intervals of estimated effects of PIT under each scenario 49

Confidence intervals of estimated effects of VAT under each scenario 52 
Figures

Figure 1

Figure 2

Decile shares of the post-2011 PIT consolidated relief allowance

26

Figure 3 Lorenz curves under base, pre-2011 and post-2011 PIT scenarios

55

Lorenz curves under base, pre-2020 and post-2020 VAT scenarios

55 


\section{Acknowledgements}

This paper was produced with the support of the International Centre for Tax and Development (ICTD), in close collaboration with the Nigerian Tax Research Network (NTRN). ICTD is financed by the Bill and Melinda Gates Foundation. I am very grateful to Kalle Hirvonen for providing the STATA program do files which I adapted for the microsimulation analysis in this paper. I also specially thank Giulia Mascagni for very useful suggestions that improved the policy relevance of this paper. I thank the World Bank and the Nigeria National Bureau of Statistics (NBS) for making the Nigeria Living Standard Survey data publicly available. I am also thankful to the NTRN Research Coordinator, Olly Owen, and to two anonymous reviewers whose comments and suggestions were useful in improving the quality of this study.

\section{Acronyms}

ATAF

AUC

CIT

CRA

ETR

GDP

ICTD

NBS

NLSS

OECD

PAYE

PIT

SDG

VAT
African Tax Administration Forum

African Union Commission

Company income tax

Consolidated relief allowance

Effective tax rate

Gross domestic product

International Centre for Tax and Development

National Bureau of Statistics

Nigeria Living Standards Survey

Organisation of Economic Corporation and Development

Pay As You Earn

Personal income tax

Sustainable Development Goals

Value added tax 


\section{Introduction}

Nigeria recorded robust economic growth averaging 7.1 per cent per annum in 2000-2014, and as at then, growth was higher than the average population growth rate of 2.6 per cent (World Development Indicators (WDI) 2020). In 2014, the country attained a gross domestic product (GDP) rebased at $\$ 510$ billion and became the biggest African economy (National Bureau of Statistics (NBS) 2014; World Bank 2019). However, with the 2014-15 oil shock, the economy's growth rate plunged to 2.7 per cent in 2015 and further down to -1.6 per cent in 2016. Though a gradual recovery has been observed since 2017, the Covid-19 related disruptions (lower oil prices and remittances, together with mobility restrictions) reversed Nigeria's growth back to negative level (-1.8 per cent), resulting in the 2020 economic recession (World Bank Group 2020; WDI 2020).

Despite strong economic growth in the earlier part of the decade (2000-2014), poverty reduction process remained slow (World Bank 2016). This was deepened by the 2014-15 oil shock, culminating in a declined living standard, as the sustained high population growth rate exceeded the growth rate of the economy (World Bank Group 2019). Consequently, the poverty rate has been on the rise, from 26 per cent in 1980 to 46 per cent in 2004 (NBS 2012; World Bank 2013). Although a decline to 35 per cent was observed in 2010 (World Bank 2013), it has risen from 35 per cent seen in 2010 to 41 per cent more recently, in 2019 (World Bank 2013; NBS 2020). And significant regional differences still exist, with poverty level up to 52.1 per cent in rural regions, but only 18 per cent in the urban part of the country (NBS 2020). More so, income inequality, as measured by the Gini index, worsened from 0.36 in 2004 to 0.41 in 2013 (NBS 2018). Though inequality marginally declined to 0.40 in 2016 (NBS 2018), the latest Commitment to Reducing Inequality Index (CRI) ranking reveals that the country remains at the bottom (Development Finance International and Oxfam 2020). In such an uncertain economic and social environment, there is considerable interest in exploring not just the costs and benefits of various policy options, but also their equity and redistributive attributes. The worrisome question becomes: is the Nigerian government making an optimal use of the policy instrument of taxation to achieve its goal of inequality and poverty reduction?

In this context, this study not only assessed equity of taxation reform, but its effect on income inequality and poverty levels in Nigeria. The redistributive effect of taxation is of policy significance when, first, we are interested in the proportion of resources (disposable income) households may be left with to purchase other basic goods after making tax payments and, second, for other equity reasons. This will help us to clearly understand how the burden of personal income tax (PIT) and value added tax (VAT) are distributed across individuals, households, and groups of people. This study focuses on personal income tax, collected directly from the household as a key tax policy tool to achieve greater equity and redistribution. The focus on income taxation in Nigeria is motivated by the relatively most recent policy on its structure, adopted in 2011 . Hence, it is timely to evaluate its progressivity and redistributive effects in the country. The 2011 tax system was derived from the old personal income tax (PIT) 1993, updated as the 2004 Act, with the aim to align with changes in the income of Nigerians. The most recent tax policy, however, replaced several controversial sections of the old act by not only changing the income tax table, but replacing all reliefs, including personal relief allowance, with a consolidated relief allowance (CRA) of \#200,000 1 plus 20 per cent of gross income, with extra 8 per cent pension allowance. The latest law hence aims to provide a kind of tax relief, reduce the tax burden on all individuals, especially lower income earners, increase workers' disposable income so that they can adjust for the effect of inflation and the high cost of living, and eliminate some of the loopholes that were previously being used to exploit taxpayers. Overall, the new

Nigerian Naira: official exchange rate as of 1 January 12021 was 1 US dollar $(\$)=380$ Nigeria Naira (\$). 
amendments are meant to bring down income tax for many individuals in accordance with the national tax policy objective of reducing direct tax. Bearing these latest policy reforms in mind, one would specifically ask: to what extent has the most recent tax reform (including mainly the lump sum relief allowance) affected the tax burden of the individual income taxpayer in Nigeria? Growing literature for developing countries on the effect of tax relief allowances and deductions on equity and income redistribution argues that lump sum tax relief deduction tends to mainly favour rich taxpayers, and hence worsen equity and redistribution of income. Although tax relief and deductions are introduced and driven by equity objectives, to help improve the welfare of individuals in the low-income class, extant empirical studies (Avram 2017; Cano 2017; Inchauste and Rubil 2017) reveal that the relief deductions mainly benefit the individual taxpayers at the top of the income class, relative to the taxpayers in the low-income category. The current study examined this issue, for the first time in the context of Nigeria, by looking at the counterfactual ${ }^{2}$ simulated effect of the recently introduced lump sum relief allowance ( $\$ 200,000$ plus 28 per cent of income) on the equity and redistribution of the income tax policy tool.

Further, this paper focuses on VAT as a major indirect tax policy tool used in manipulating the distribution of resources in Nigeria. It directly affects individuals, and accounts for a significant fraction of the country's total indirect tax revenue. ${ }^{3}$ The focus on the redistributive potential of VAT is mainly motivated by the recent increase in VAT by the Nigeria federal government, from its 5 per cent rate since 1993 to 7.5 per cent in 2020. It is indeed timely, however, to examine the likely effect of this policy change (a 50 per cent increase in VAT rate) on poverty and income inequality in Nigeria. VAT, which replaced the sales tax, was first introduced in Nigeria through the decree No. 102 of 1993 and became effective on 1 January 1994. Since this period, the VAT in Nigeria has remained at the rate of 5 per cent. Bearing in mind the fact that the Nigerian VAT rate is one of the lowest among peer countries (e.g. Ghana and South Africa), the Federal Executive Council proposed on 11 September 2019 a new VAT rate of 7.5 per cent for the country, up from the current 5 per cent. Following from the above, therefore, this research attempts to broaden our understanding of tax and development issues by analysing for the first time the extent to which the relatively recent income tax policy reform has affected the distribution of income and poverty levels. Further, the study tries to, for the first time, take into account the possible effect of the new policy of a 50 per cent increase in VAT on household income inequality and poverty levels. Hence, it is expected that the results of this study will help to inform policy makers who are interested in tax equity issues with options to better reform the country's tax financing systems.

Currently, literature on the redistributive effect of personal income tax in Nigeria appears to be very scanty. A related available published article (Egbon and Mgbame 2015) in Nigeria is plainly a conceptual analysis of personal income tax progressivity, with no effort to analyse any form of micro household survey data. Ichoku and Anuku (2019) only used state level (i.e., very small sample) data to analyse the effect of only personal income tax on income inequality, ignoring its effect on poverty levels in Nigeria. Other studies (Obaretin, Akhor and Oseghale 2017; Anyaduba and Otulugbu 2019) on this issue in Nigeria have only used macro level time series data, which is clearly unable to rigorously speak to equity and redistribution issues at the household level. The current study, however, attempts to use the most recent large nationally representative household survey to quantitatively analyse at the micro level not just the progressivity of personal income tax, but its effect on both income inequality and poverty levels in Nigeria. Ascertaining whether a tax policy is progressive or regressive is not enough to figure out its effect on inequality and poverty. Hence, the need to also estimate the marginal contributions of taxes on inequality and poverty levels (Inchauste

A counterfactual effect predicts what would happen (in this case to progressivity and redistribution) if changes in the distribution of the relief allowance were to be implemented.

Revenue from value added tax is about 54 per cent of total indirect tax revenue in Nigeria. See Table 1 below. 
and Lustig 2017). Further, to the best of the author's knowledge, the current study is the first in Nigeria that attempts to analyse the extent to which the 2011 income tax reform has affected the distribution of income and poverty within the country. More so, to the best of the author's knowledge, quantitative household-level micro studies on progressivity and the redistributive effect of value added tax reforms in Nigeria are very rare. For instance, available studies (Oboh and Eromonsele 2018; Anyaduba and Otulugbu 2019) on the effect of value added tax on income inequality in the country have mainly used macro level time series data, with little or no effort to investigate its effect on poverty levels. Hence, to extend existing knowledge and contribute to defining recommendations on a nuanced approach to fighting poverty and bridging the income gap between the poor and the rich, the current study carried out a household-level micro analysis of the progressivity and the distributional effects of income tax and value added tax reforms on various poverty indices (poverty headcount, poverty gap and poverty severity) and income inequality across national and regional levels using the standard Kakwani Index and simple static micro-simulation model.

It is crucial to note at this point that research works on taxation and development in developing countries have tended to ignore informal tax systems, usually focusing on formal taxes alone. However, it is widely known that people in the informal sector hardly contribute to formal taxes - income or value added taxes. Recently, growing research on taxes in low and middle-income countries suggests that the partial focus on formal taxation often fails to observe crucial systems of informal taxation involving tax-like payments (user fees/community development levies, chiefdom levies etc.) made in rural communities, outside statutory tax laws. This leads to erroneous comprehension of local household tax burdens, together with the dynamics of provision of local public goods, and so of governance in the local context (e.g. Jibao, Prichard and van den Boogaard 2017; van den Boogaard, Prichard and Jibao 2018).

The current study, however, does not claim to have explicitly studied these informal taxes, mainly due to limitations in the data. Accordingly, it is crucial to clearly note that the survey data used in this study does not contain reliable variables on informal tax-like payments, which would enable a rigorous analysis of informal taxes in Nigeria. To depict informality, however, the paper at best provides only a simple comparative description of the size of the formal and the informal sector, as well as the corresponding average earnings of households within these sectors. This mainly comprises the proportionate mean incomes of formally and informally engaged individuals per specific household (see 5.1, Table 2). Further, the paper attempts to account for informality by failing to impose the tax rules on informal earnings, assuming that individuals within the informal sector (e.g. the self-employed) do not contribute to formal taxes. This is intentionally done to see what incidence of taxes and redistribution will look like in the presence of tax administration corrected for informality, relative to what these results will look like if informality is entirely ignored.

In summary, the equity outcomes, as measured by the Kakwani Indices, reveal that the PIT was progressive in the pre-2011 tax scheme but turned regressive in the post-2011 tax scheme, after informality has been put into consideration. It was also uncovered that capping the relief allowance of the post-2011 tax scheme reduces the regressivity of the PIT indirectly implying that the lump sum relief deductions of the current income tax scheme accrued more to the high-income than to the low-income taxpayers. In justification of this finding, the post-2011 PIT became clearly progressive when the variable part of the lump sum relief allowance was given to only the low-income taxpayers below a predefined income threshold, entirely excluding high-income taxpayers above or equal to the threshold. The above regressivity finding of the post-2011 income tax scheme (when the lump sum relief is left unrestricted) is similar to that of previous related works (e.g. Hirvonen, Mascagni and Roelen 2016; Mascagni, Monkam and Nell 2016), showing that tax systems initially designed to be progressive can still be regressive in practice. VAT was found to be regressive both in the pre-2020 scheme and in the current reform scheme. In terms of the redistributive effect, 
the simulation results reveal that although the PIT marginally reduced inequality, it conversely increased poverty in the pre-2011 scheme. More so, the post-2011 PIT negative effect on inequality and positive effect on poverty was found to be minimal. The slight reduction in inequality as measured by the Gini index is consistent with previous works (e.g. Hirvonen et al. 2016), reporting a negligible effect of income taxation on overall income distribution. The opposing finding of reduction in inequality and increase in poverty confirms other studies (e.g. Lustig and Higgins 2012; Inchauste and Lustig 2017), suggesting that an inequality-reducing tax system could also be poverty increasing. However, if relatively highincome taxpayers above or equal to a predefined income threshold are entirely excluded from sharing in the variable part of the post-2011 lump sum relief allowance, a larger redistributive effect is observed. The VAT in the pre-2020 scheme was uncovered to marginally increase inequality and poverty in Nigeria. Although the current VAT scheme slightly increased inequality, it considerably increased poverty - a finding similar to what Hill, Inchauste, Lustig, Tsehaye and Woldehanna (2017) reported for Ethiopia. It is further revealed that tax progressivity and the redistributive effect tend to be overestimated when informality is entirely assumed away (i.e. not accounted for).

The current study has several limitations. First, the study is unable to directly apply the tax laws on informal sector earnings, since the informal sector activities evade taxes. Hence, in accounting for informality in PIT, the tax laws have only been directly applied on the formal sector earnings. Further, in an attempt to account for informality in consumption taxes, the study calculated and applied the effective VAT rates on taxable household consumption expenditures. Although this approach is in line with that of some previous studies (e.g. Arunatilake, Inchauste and Lustig 2017; Cancho and Bondarenko 2017; Younger and Khachatryan 2017), it also differs from the approach utilised in some other recent papers (e.g. Bachas, Gadenne and Jensen 2020). The current study shows that even when informality is accounted for, consumption taxes remain regressive, with little or no redistributive effect - a finding in line with those of Arunatilake et al. 2017 and Younger and Khachatryan 2017, among others). However, this finding is unlike that of Bachas et al. 2020, who show that accounting for the informal sector makes consumption taxes progressive. The varying findings could be attributable to the differing approaches used in addressing informality in consumption. Unlike the survey datasets containing place of purchase data, used by Bachas et al. 2020 to proxy informal consumption, the survey data used in the current study does not clearly provide information on the type of stores in which specific purchases occurred (making it difficult to identify informal sector purchases). This presents a limitation, so that the current study is only able to follow other related works in applying effective VAT rates in addressing consumption informality. The second limitation is that the study had no access to administrative data containing the real income tax amount reported by taxpayers. Hence, following existing studies, it obtained a proxy variable for income tax by applying the tax rules on formal incomes of individual households. Third, although the study has accounted for the quality of income variable using the consumption expenditure from the survey data, it still acknowledges the limitations which mainly entail that surveys exclude the top income earners. Also, household surveys are widely known to understate income, since people tend to underreport their own income during survey data collection. Hence, it is assumed in this study that correcting for income underreporting using 'better' collected consumption data provides a 'better' living standard measure for correct analyses. Fourth, this study has not accounted for company income tax (CIT), since there is no properly recorded information in the used survey to account for CIT. Hence, the main analyses in this work only focus on taxes (PIT and VAT) relevant to households, and not on CIT, which involves several uncertain assumptions, making it very difficult to ascertain the distribution of its final economic incidence (Ataguba 2012; Inchauste and Lustig 2017). Fifth, due to data limitations, this study has assumed a very simple static micro-simulation model, unable to study the entire fiscal system, and account for dynamic effect. It has, in a static sense, mainly considered the effect of two specific taxation policies (PIT and VAT), rather than the entire fiscal system. Despite these limitations, the study makes a useful contribution to the 
discussion of the equity and redistribution implications of tax reforms in developing countries. In line with previous related studies, it specifically shows that tax systems theoretically designed to be progressive can still become regressive in practice. The income tax regressivity found in the current study is mainly attributable to the concentration of the lump sum relief allowance within the top of the distribution. Hence, it is revealed that placing a cap on relief allowance helps to reduce the regressivity of the income tax scheme. Even more interesting is that entirely excluding relatively high-income taxpayers above or equal to a predefined income threshold from sharing in the variable part of the lump sum relief allowance makes the post-2011 PIT clearly progressive. Consumption taxes remain regressive. These all together call for policy attention towards the restriction of the variable part of the lump sum relief allowance in the post-2011 PIT scheme and the adoption of differentiated VAT rates.

The rest of the paper is organised as follows. Section 1 presents a review of previous related literature. Section 2 describes the structure of tax revenue, together with a description of the key insights to the 2011 PIT Act, relative to the old PIT Act in Nigeria. Section 3 lists the objectives of the study. Section 4 describes the dataset and methodology - specifically consisting of data sources, methods for variables calculations, techniques used in accounting for informality and methods for calculating progressivity and the redistributive effect of PIT and VAT. Section 5 details the results and corresponding interpretations. Section 6 discusses and concludes the paper.

\section{Literature review}

In general, there have been many studies on equity (incidence) and the redistributive effect of both PIT and VAT (effect on poverty and income inequality) across the globe. This ranges from studies conducted for developed countries (e.g. OECD countries), to works done for developing countries (selected low- and middle-income countries). In terms of incidence of PIT, most studies, aside from a few (Hirvonen et al. 2016; Mascagni et al. 2016) have reported this policy instrument to be progressive. For instance, Cubero and Hollar (2010) reported that PIT is usually progressive in Central America. In Bangladesh, Sarker (2006) revealed that those with higher incomes pay a larger fraction of their income in taxes, relative to those households with a smaller income - this implies a progressive income tax in Bangladesh. Nyamongo and Schoeman (2007) analysed reform in income tax progressivity in South Africa and found an increase in progressivity during the first phase of the reform programme, but a decrease in progressivity during the second phase of the reform. This they attributed to the fact that many more new taxpayers entered the tax net, making the distribution of pre-tax income more unequal. In selected OECD countries (e.g. Portugal, Belgium), Warren (2008) disclosed that income taxes are indeed progressive. For the European Union (Greece, Netherlands, Spain, Belgium, the UK), Verbist and Figari (2013) found that the PIT is the most crucial source of progressivity, and hence reduces income inequality. Supporting the above evidence, Inchauste, Lustig, Maboshe, Purfield and Woolard (2015) discovered a progressive income tax system in South Africa, since the richer deciles pay a proportionally higher share of total direct tax collections than their share of market income. Sarah and Kasirye (2015) also uncovered that the Uganda 2012/2013 income tax reform enhanced the progressivity of Pay As You Earn (PAYE) in the country. Inchauste and Rubil (2017) report that the recent changes in income taxes (e.g. increased threshold for the top rate and increased personal allowance) in Croatia made the policy instrument more progressive in relative terms in 2017 compared to 2014, as poorer households paid lower taxes as a share of their incomes. Contrary to the above outcomes, studies such as Hirvonen et al. 2016 (for Ethiopia) and Mascagni et al. 2016 (for Rwanda) unpacked that tax systems initially designed to be progressive on paper can still turn to be regressive in practice. 
Regarding the redistributive effect of PIT, while some extant studies have revealed it to possess negligible effect on income distribution, some other papers (e.g Martinez-Vazquez, Moreno-Dodson and Vulovic 2012; Inchauste et al. 2015; Du and Zhang 2018) have shown more significant effect. For example, Cubero and Hollar (2010) revealed that since income taxes contribute a marginal fraction to an already small income tax revenue across Central America, their overall effect on inequality is quite small. Bird and Zolt (2005) reported that income tax alone is not enough to redistribute income in developing countries, since it plays a limited role in reducing income inequality. Engel, Galetovic and Raddatz (1999) found that income tax has little incremental effect on the Gini coefficients in Chile, and this also holds even after significant modification of tax structure in the country. Contrariwise, Inchauste et al. (2015) found that since income taxes make up a relatively high share of the GDP, they contribute significantly to the gap between the rich and the poor (income inequality) in South Africa. Similarly, Martinez-Vazquez et al. (2012) have shown that progressive income taxes have a positive impact on income distribution, contributing to decreasing inequality, and this effect is more significant the larger the extent of progressivity and the larger the share of GDP that is collected from income taxes for some large panel of countries. The work of Du and Zhang (2018) using the generalised entropy index shows that the 2011 PIT adjustment in China has effectively reduced income inequality, but within the high-income group. Opposing this finding, Hirvonen et al. (2016) revealed that income taxation has a negligible effect on Ethiopia's Gini index. In line with Hirvonen et al.'s findings, Popescu, Militaru, Stanila, Vasilescu and Cristescu (2019) uncovered that the PIT policy reform in Romania led to a modest effect on income inequality. Causa and Hermansen (2017) found for the OECD countries that the personal income taxes played a less important and more heterogeneous role in income redistribution. In Uganda, Jellema, Lustig, Haas and Wolf (2016) uncovered that PIT engenders a modest reduction in income inequality, whereas Inchauste and Rubil (2017) discovered that income taxes are significantly redistributive in Croatia.

Worthy of note is that the literature provides mixed and varying evidence on the incidence and redistributive effect of VAT across various countries. For OECD countries (e.g. Portugal, Belgium), Warren (2008) reported that the VAT is regressive, though some variations exist across these countries. For instance, VAT in Belgium was found to be less regressive than VAT in Portugal. In the context of developing countries, Faridy and Sarker (2011) uncovered in their study in Bangladesh that VAT is regressive as it is applied at a flat rate regardless of the size of income of the household. In a similar developing country context, Gemmel and Morrissey (2005) disclosed that taxes on goods consumed especially by poor households are mostly regressive, whereas taxes on luxury goods, for example cars, are mostly progressive. In line with these findings, Cubero and Hollar (2010) have shown VAT to be regressive in most Central American countries. Contrary to the above regressivity findings, Rafaqat (2003) revealed that the incidence of goods and services tax (GST) is slightly progressive in Pakistan. Rafaqat attributed this progressivity outcome to the fact that most goods mainly consumed by poor households are excluded from GST in Pakistan. Similarly, Sivashankar, Rathnayake, Jayasinghe and Smith (2017) disclosed the incidence of VAT to be somewhat progressive in the Sri Lanka context. Toe, Diallo, Barhoumi, Towfighian and Maino (2017) uncovered in Benin that VAT is progressively distributed, since richer households account for larger VAT shares. More recently, Bachas et al. (2020) revealed through their work that accounting for the informal sector makes consumption taxes progressive in some selected developing economies. For the Dominican Republic, Jenkins, Jenkins and Kuo (2006) also found that VAT is progressive, and that this is so even when the base of the VAT is made more comprehensive. In other words, wealthy households pay effective VAT rates that are on average 2.5 times higher than the rates faced by poor households. In mixed findings, Sarah and Kasirye (2015) show that, in Uganda, when the VAT base is broadened, it becomes progressive for certain goods (e.g. milk), regressive for other goods such as salt and inconclusive for some others such as processed corn. In a more recent study, Thomas (2020) revealed a small extent of progressivity in nearly all 
selected OECD countries, with the exception of countries such as Chile, Hungary, Latvia and New Zealand involving a negligible proportion of regressivity.

In terms of the redistributive effectiveness of VAT, the current study observed mixed outcomes as well. While some existing studies (e.g. Cubero and Hollar 2010; Toe et al. 2017) report a significant redistribution from the VAT policy instrument, others such as Engel et al. 1999, Schmutz and Schaltegger 2018 and Thomas 2020 disclose a less significant effect. For instance, in Chile, Engel et al. (1999) found that a significant increase in VAT from 18 per cent to 25 per cent resulted in an insignificant effect on after-tax income distribution. Inchauste and Rubil (2017) used a simulation approach to show that in Croatia reducing the statutory VAT rate from 25 per cent to 24 per cent would negligibly reduce inequality but would bring down poverty by 0.21 per cent. Phillips, Warwick, Goldman, Goraus, Inchauste, Harris and Jellema (2018) uncovered that although low VAT rates on commodities, such as foodstuffs and kerosene, reduce poverty, they are not properly directed towards the poorer households in selected low- and middle-income countries (Ethiopia, Ghana, Senegal and Zambia). Toe et al. (2017) show that in Benin, although VAT reduces income inequality, it contributes to an increase in the poverty headcount rate. Cubero and Hollar (2010) report that since VAT is an important source of revenue in most Central American countries, its effect on inequality is significant. Similarly, Blasco, Guillaud and Zemmour (2020) recently found that taxes for consumption produce a reasonable rise in the Gini index (ranging from 0.01 to roughly 0.05 points) for a panel of selected countries (Australia, France, Germany, Ireland, United Kingdom and United States). They also concluded that variation across countries in the consumption tax redistributive effect are majorly defined by varying tax rates (ranging 7 per cent to 30 per cent). Opposing the first finding of Blasco et al., Schmutz and Schaltegger (2018) used Swiss data to uncover that the current VAT rate has no significant redistributive effects on income inequality. But they also reveal that differentiated VAT rates have some redistributive impact, since households in the higher deciles of consumption expenditures have, on average, a larger share of expenditures taxed at normal VAT rate, relative to households in the lower deciles. For some 27 OECD countries, Thomas (2020) revealed the VAT to possess a minimal redistributive effect, and this comes from the minute extent of progressivity of the tax instrument. Notably, the results of Blasco et al. (2020) also revealed that VAT raises the number of people below the line of poverty.

Although the incidence and redistributive effect of PIT and VAT have been well studied across several developed and developing countries, these issues have not been sufficiently addressed in certain low- and middle-income countries - particularly the context of Nigeria. As noted above, related studies in Nigeria (e.g. Egbon and Mgbame 2015) are merely a conceptual analysis of only the incidence of PIT. Some others (e.g. Anyaduba and Otulugbu 2019) which are also partial analyses have only used macro (aggregate) data which is not able to specifically point to individual household taxes and their particular effects on welfare at the micro household level. Hence, the motivation for the current study to fill these gaps.

\section{Structure of tax revenue in Nigeria}

Table 1 below gives a breakdown of the major Nigerian government tax revenue sources, and also identifies specific tax components that were included in the incidence analyses. Overall, Nigeria tax revenue as a share of GDP within the 2018 period was only 6.3 per cent. This is 10.2 percentage points below the African (30 countries) average tax-to-GDP ratio of 16.5 per cent, and also 16.8 percentage points below the Latin American/Caribbean average values within same period respectively (OECD/AUC/ATAF 2020). Of Nigeria's total tax revenue in 2018, direct taxes contributed the largest share of roughly 60 per cent, with the bulk of the share (about 50 per cent) coming from corporate income taxes. This was followed by the total indirect tax proportion of 25 per cent, with the major part of it collected from the 
value added taxes (roughly 14 per cent). The incidence and redistributive analyses in this paper focus on PIT and VAT, covering about 24 per cent of the total tax revenue collections. These are the main direct and indirect taxes, of which their respective burdens are readily identifiable to specific households. Other direct (corporate taxes) and indirect taxes (e.g. excise and custom taxes) as seen in Table 1 below have been excluded from the analyses following difficulty in attributing the respective taxes to particular households using the Nigeria survey data. Finally, aside from the corporate income taxes and value added taxes contributing 3.2 per cent and roughly 1 per cent shares to the GDP, other tax components individually contribute less than 1 per cent share to the Nigeria GDP in the 2018 period.

Table 1 Structure of tax revenue in Nigeria, 2018

\begin{tabular}{|l|l|l|l|l|}
\hline Revenue source & Total (N' million) & $\begin{array}{l}\text { Share of total } \\
\text { taxes }(\%)\end{array}$ & $\begin{array}{l}\text { Share of GDP } \\
(\%)\end{array}$ & IA? \\
\hline Total tax revenue & $8,167,037$ & 100 & 6.3 & No \\
\hline Indirect taxes & $\mathbf{2 , 0 4 7 , 8 6 0}$ & $\mathbf{2 5 . 1}$ & $\mathbf{1 . 6}$ & No \\
\hline Value added tax & $1,108,040$ & 13.6 & 0.9 & Yes \\
\hline Excise taxes & 55,060 & 0.7 & 0.04 & No \\
\hline Custom and import taxes & 884,760 & 10.8 & 0.7 & No \\
\hline Direct taxes & $\mathbf{4 , 9 1 0 , 2 6 0}$ & $\mathbf{6 0 . 1}$ & $\mathbf{3 . 8}$ & No \\
\hline Personal income tax & 798,630 & 9.8 & 0.6 & Yes \\
\hline Corporate income tax & $4,111,631$ & 50.3 & 3.2 & No \\
\hline Social security contributions & $\mathbf{6 8 7 , 0 8 0}$ & $\mathbf{8 . 4}$ & $\mathbf{0 . 5}$ & No \\
\hline Other taxes & $\mathbf{5 2 1 , 8 3 7}$ & $\mathbf{6 . 4}$ & $\mathbf{0 . 4}$ & No \\
\hline
\end{tabular}

Source: Author's calculation based on macroeconomic data from the Nigeria Federal Inland Revenue Service (FIRS). Currently, the Nigeria 2018 macro tax revenue composition data is the latest available, detailed and most reliable from the FIRS.

Notes: ${ }^{1} \mathrm{~N}=$ Nigeria Naira. IA? = included in incidence analyses?

2 Social security contributions mainly comprise both employees' and employers' national pension commission and national health insurance varying contributions.

${ }^{3}$ Other taxes mainly comprise taxes on goods and services other than VAT.

\subsection{Key insights to the 2011 PIT Act, relative to the old PIT Act}

Below, the study examines salient changes in the 2011 PIT Act, relative to the old PIT Act.

The Personal Income Tax (PIT) Act No. 104 of 1993 was the principal act regulating the PIT administration in Nigeria until it was altered as the PIT Act, Cap. P8 Laws of the Federation of Nigeria (LFN) 2004, and subsequently amended in 2011 as the PIT (Amendment) Act 2011. The principal act (pre-2011) states some several separate personal allowable allowances (tax reliefs), which include housing, meals, utilities and other things. But these reliefs were all merged into one in the 2011 Act. For instance, the principle act states that 'Tax shall be payable for each year of assessment on the aggregate amounts of income of every taxable person, for the year, other than the following allowances: rent allowance paid by the employer to the employee not exceeding $\$ 100,000$ per year; transport allowance of the employee not exceeding $\$ 15,000$ per year; meal allowance of a maximum of $\$ 5,000$ per year; utility allowance of $\$ 10,000$ per annum; and entertainment allowance of $\$ 6,000$ per annum'. However, these separate allowances were abolished and updated in the amended 2011 Act and brought together as one consolidated relief allowance in the computation of the tax liability of an employee (Federal Republic of Nigeria 1993, 2011).

By section 33 of the principal act, an employee is also granted a personal tax relief or allowance of $\$ 5,000$ plus 20 per cent of earned income. But the 2011 act consolidates all these allowances and reliefs to mainly include $\$ 200,000$ plus 20 per cent of gross income. Gross income (or emolument) is defined to comprise in-kind benefits and any other income derived solely from employment. Thereafter, the following deductions are tax exempt under the 2011 act: national housing fund (NHF), national health insurance scheme (NHIS), life assurance premium (LAP), and national pension allowance. After these deductions are 
made; the remaining balance is taxable in accordance with the new tax table (see Table 10 in the appendix). Notably, the current study has only accounted for the national pension allowance - 8 per cent of income in addition to $\$ 200,000$ plus 20 per cent of income (applicable to roughly all Nigerian employees both in the government and private sectors) in the computation of the amount of tax payable in the post-2011 scheme. This is simply because, in reality, deductions such as the NHF, NHIS, and LAP are not usually applicable across all workers. As observed from selected workers' pay slips, for instance, some federal government workers contribute to NHF, but this is not quite applicable to government workers across all levels and most workers in the private sectors. And it is unlikely that the tax authorities will grant these allowances (NHF, NHIS, and LAP) (PricewaterhouseCoopers (PwC) 2012).

Further, the 2011 act increased the minimum tax rate payable by an employee from 0.5 per cent to 1 per cent of the gross income below the minimum taxable income per annum. The graduated rate of income tax is adjusted as follows; the first and last incomes to be taxed in the pre-2011 act are $\$ 20,000$ and $\$ 120,000$ at corresponding rates of 5 per cent and 25 per cent respectively. However, these were adjusted in the 2011 act to include: the first and last income to be taxed as $\$ 300,000$ and $\$ 3,200,000$ at corresponding rates of 7 per cent and 24 per cent respectively (PIT Act 1993; PIT (Amendment) Act 2011). For detailed breakdown of these income tax bands and corresponding rates see tables 9 and 10 in the appendix. As noted in the introduction above, the 2011 reforms were designed to reduce the income tax burden of all individuals, mainly the poor people in line with the national tax policy objective of reduction in the burden of direct tax in the country (PwC 2012).

\section{Research objectives}

The broad aim of this research is to assess the equity and redistributive effects of taxation reforms in Nigeria. Specific objectives include:

1. To assess the progressivity of income tax and value added tax reforms in Nigeria.

2. To assess the distributional effect of income tax and value added tax reforms in Nigeria. This second objective is specifically further broken down into:

i. To estimate the effect of income tax and value added tax reforms on poverty levels in Nigeria.

ii. To estimate the effect of income tax and value added tax reforms on income inequality in Nigeria.

\section{Data and methodology}

\subsection{Data sources}

The study will mainly use the most recent large scale nationally representative survey dataset (i.e. the Nigeria Living Standard Survey (NLSS) 2018/2019) with detailed income and expenditure information. The NLSS is representative of the 36 states in Nigeria and Federal Capital Territory (FCT), Abuja, with its sample covering around 22,110 households. The survey covers a wide and diverse set of socio-economic and demographic data concerning basic needs and the conditions under which households live on a day-to-day basis. It is collected through two major different survey questionnaires. These are the household and the community questionnaires. The current study utilised information from the household questionnaire. The household questionnaire provided information on demographics; 
education; health; labour; food and non-food expenditure; household non-farm income generating activities; food security and shocks; safety nets; housing conditions; assets; information and communication technology; agriculture and land tenure; and other sources of household income. In terms of the sample size determination, 60 enumeration areas (EAs) were selected per state with ten sampled households per EA. This resulted in an initial sample of 600 households per state and an overall sample size of 22,110 households. The survey is produced by the Nigeria NBS with technical assistance from the World Bank. Financial support for the survey came from the Federal Government of Nigeria, the World Bank, and the National Social Safety-Net Coordinating Office (NASSCO). ${ }^{4}$

\subsection{Variables calculations (computing taxes, and adjusting for income underreporting)}

First, the tax information is not directly reported in the NLSS, so the study cannot use the 'Direct Identification Method' to directly obtain the taxes. Hence, as suggested in Lustig and Higgins 2012, the current study used the 'Simulation Method' i.e. it calculated the taxes (PIT and VAT) from available information in the survey (income and consumption expenditure data), assuming that the economic burden of PIT and VAT is borne by the income earner and the consumers in line with conventional tax incidence analyses. Second, the survey contains a detailed income module that attempts to measure household income as correctly as possible. However, in measuring the living standard of the household, consumption expenditure has been widely noted to be easier to collect in household surveys, less prone to fluctuations, and as a result more reliable than household income (Deaton and Zaidi 2002). More so, household surveys have a tendency of under-computing incomes, because people might on purpose or by accident underreport their own incomes, surveys might fail to ask sufficient questions to capture certain categories of income, and on the whole miss top income earners in the society (Atkinson, Piketty and Saez 2011). Consequently, income is measured with significant error, and failing to adjust for income underreporting in the current study involving the imputation of income taxes to households by applying the prevailing tax laws would lead to underestimation of the incidence and redistributive effect of the PIT. Hence, this makes its direct use in this study less appealing.

In this study, however, using consumption data directly poses a significant challenge, since the tax simulation requires applying tax rates on wage income component alone. That is, out of other income components, the proportion of labour income in total consumption will be determined. In Nigeria, for instance, income taxes are mainly paid by employees in the formal sector, so that PIT is calculated separately based on the PAYE system for paid employment, rather than being applied to the aggregate income components. Hence, to attempt to deal with this issue, the study followed Hirvonen et al. 2016 to use the following steps. First, this study calculated the shares of household total income coming from different income sources (agricultural and labour wages, crop income, livestock income, income from self-employment, and other income (e.g. income received from land and non-land assets)). Second, it multiplied these shares by the total consumption of the household, dividing the household consumption into the income components. Finally, it applied tax rates on the labour wage component before re-computing the total household consumption variable. By following this process, however, the work might judge too highly the total tax payments for households that have more than one wage earner. However, it is crucial to note that the majority of households in the data have only one wage earner. By taxing incomes at the household level together, rather than separately, the study applied higher marginal rates on relatively high incomes. To account for household size, this work utilised per capita measure in adjusting aggregate consumption. ${ }^{5}$

The 2018/2019 NLSS dataset can be accessed through the following link: http://microdata.worldbank.org/index.php/catalog/3827

Consumption aggregate should be adjusted to account for household size, using per capita or equivalence scale measure. The current study chose per capita estimate, since it is mostly commonly available and because the existence 


\subsection{Accounting for informality in PIT and VAT}

Informality in payment of personal income tax was accounted for by following existing related studies (e.g. Younger and Khachatryan 2017; Cancho and Bondarenko 2017) to assume that only formal sector employees pay taxes, while self-employed individuals and employees of the informal sector do not pay taxes. Indeed, this is applicable to Nigeria, where individual income taxes are assumed to be mainly paid and borne by labour in the formal sector (Adekanola 1997). This implies that informal sector workers tend to dodge income taxes and hence may not share in the burden. In Nigeria, taxes are mainly paid by employees in the formal sector, since there are records, and they are deducted from the source (Adekanola 1997). The self-employed jobs that tend to evade taxes in the country mainly comprise activities in the informal sector. These activities, as defined in section 9 (non-farm enterprises and income generating activities) of the household questionnaire comprise carwash, metal worker, mechanic, carpenter, tailor, barber, hawking or selling anything on the street, bar, and food stand businesses etc. Because these activities are likely to evade taxes, this study did not apply the tax rules on them, instead, it applied taxes on the labour income of formally employed individuals. This enabled us not to overestimate the income tax effect in Nigeria.

In terms of value added tax, informality also exists (i.e. evasion on payment of VAT). Purchases in rural areas and informal sector establishments (markets) are more likely to evade tax. VAT evasion can either be modelled by assuming that those who purchase goods in certain areas are tax evaders, or by assuming effective VAT rates that reflect rates paid in reality, instead of statutory rates which can overestimate the impact of indirect taxes on income (Rajemison, Haggblade and Younger 2003). However, there is a lack of quality data on places of purchase of consumption items. In other words, it is not possible for the study to know from the NLSS data whether a household bought something from a business firm that pays VAT or not. Moreover, prices at firms that do not pay VAT are likely the same as those that do pay VAT, with the benefits of non-payment going to the owners of the firm. This implies that households suffer the burden of the tax regardless of the tax status of the seller (Arunatilake et al. 2017). Hence, to account for informality and evasion of value added tax, this study followed related papers (e.g. Jellema, Wai-Poi and Afkar 2017; Arunatilake et al. 2017; Younger and Khachatryan 2017) to apply an effective VAT rate (rather than the statutory rate) to all household purchases excluding exempt goods. The effective rate of the VAT was calculated as the ratio of total VAT revenue collections to the total consumption value of all goods subject to VAT (the taxable base). The proportion of VAT was then estimated by applying the effective rate to household expenditures, excluding the exemptions provided by the tax code. Although this approach is in line with that of the previously mentioned studies, it also differs from the approach utilised in some other recent papers (e.g. Bachas et al. 2020). Unlike the survey datasets containing place of purchase used in Bachas et al. to proxy informal consumption, the survey data used in the current study does not clearly provide information on the type of stores in which specific purchases occurred (making it difficult to identify informal sector purchases). This presents a limitation, so that the current study is only able to follow other related works in using effective VAT rates in addressing the consumption informality issue.

\subsection{Method to assess the progressivity of PIT and VAT}

To measure the progressivity of PIT and VAT, the study utilised the Kakwani Indices relevant in financing incidence analysis, which have been applied in several related studies (e.g. Lustig, Pessino and Scott 2013; Inchauste et al. 2015). The Kakwani Index helps to reveal whether a given tax financing tool is progressive, regressive or proportional relative to ability to pay (i.e. income). Of importance to mention is that there are various methods in the 
literature for assessing progressivity. The easiest approach employed by some authors involves the comparison of various quantile proportions of income spent on payments (tax) to try to get at progressivity (Lyon and Schwab 1995). This begins by categorising households into quantiles (e.g. quintiles, deciles). For each share of the quantiles, income spent on taxes is computed. Progressivity is then determined by considering how the ratios (analogue of average tax rate) vary across quantiles. This method, however, has some limitations. First, it is not sensitive to changes that may occur close to the cut-off points for categorising households. Second, it does not show a complete picture of how the ratio of tax payments to income vary across the entire income distribution, and the precise magnitude of progressivity cannot be obtained simply by looking at these ratios (Musgrave and Thin 1948; Kakwani 1977). In response to these limitations, some more formal indices and curves in the form of the Lorenz curve, Gini index, concentration curves and indices have been developed and used in the appraisal of progressivity. Another is the Musgrave and Thin index, which simply compares inequality in pre-payment income with that of post-payment income (Musgrave and Thin 1948). However, this method has been criticised on the grounds that it mainly measures redistributive effects, instead of pure progressivity (Kakwani 1977). More so, this method is not invariant to scaling payment rates by a constant positive scalar. For instance, when all payments are increased by a given J per cent, progressivity increases. Kakwani noted that this process is not consistent with the definition of progressivity (i.e. a relative measure as opposed to an absolute measure). A measure of progressivity should not capture this effect because it measures deviations from proportionality (Kakwani 1977). As a result, the application of the Musgrave and Thin method in present day empirical usage has been limited. Hence, to deal with these limitations, Kakwani proposed an index for assessing progressivity. The Kakwani Index, which has become widely used in public economics, compares the concentration curve of tax payments with the Lorenz curve of pre-payment income.

To follow up on informality, the study provides estimates of Kakwani Index both without (formal plus informal incomes) and with informal sector correction (formal income taken alone) to enable comparison. For the incidence of income taxes, the study applied the income tax table to both the formal and informal incomes, computed their corresponding taxes, and then added them together. It then applied the added total taxes in the incidence analyses. Note that this is intentionally done, in order not to differentiate the effect of formal and informal incomes in the initial instance. Then, to enable comparison, the study accounts for informality by repeating the incidence analyses using taxes computed from only the formal incomes, ignoring the informal incomes. In terms of the VAT, the study has also presented incidence estimates both without informal sector (using statutory rate), and with informal sector correction (by applying effective rate) so as to enable comparison between the two.

\subsection{Method to assess the redistributive effect of PIT and VAT}

Progressivity analyses reveal the extent to which tax payments deviate from proportionality, but do not reveal how the distribution of income and poverty is affected by this deviation. The distributional effect of tax payments is mainly measured through the redistributive effect analysis. For instance, the redistributive effect quantifies how much more unequal (or equal) tax payments make the distribution of income (Ataguba 2012). Initially, the study aimed to use the Duclos, Jalbert and Araar (DJA) (2003) decomposition method in carrying out the distributional effect of tax payments. However, this method presents some challenges, one of which is that it requires some normative choice of values of parameter of aversion to reranking inequality (change in the order of distribution), and parameter of aversion to horizontal inequality (increase in overall income inequality resulting from unequal treatment of equals) (Duclos et al. 2003). Further, it is only based on inequality measure. This implies that it mainly examines only the income redistributive effect of tax payments (effect of taxes on income inequality alone) (Ataguba 2012) and is unable to account for its effect on poverty 
levels. This is a crucial aspect, as a tax system could decrease inequality but still lead to higher poverty levels (Inchauste and Rubil 2017). Hence, to analyse the effect of tax payments (income tax and VAT) on both inequality and poverty, the current study follows extant literature (e.g. Inchauste et al. 2015; Hirvonen et al., 2016; Inchauste and Rubil 2017) to use basic incidence analysis by constructing a simple static micro-simulation model.

The redistributive analysis using the micro-simulation model involved the computation of the inequality and poverty measures using total income/consumption variables adjusted for PIT/VAT. To adjust total income for PIT, the study first selected from the survey the taxable income components (i.e. wage/labour income). Next, it applied appropriate tax rates on this income component to get net wage income. Next, it recalculated the total incomes by adding the net wage incomes to the other non-adjusted income components (agricultural wages, crop income, and livestock income) in the survey. The final step involved the recalculation of the inequality and poverty measures using the new income total. Adjusting consumption aggregate for VAT followed a similar process. The study first selected and added up the vatable items from appropriate sections of the household survey. Next, it applied the VAT rate on the sum of the vatable items, so as to get the value of these items. Next, it recalculated the consumption aggregate by adding the net vatable items' value to the other unadjusted items (i.e. the items that are VAT exempt). The final step consisted of the recalculation of the inequality and poverty measures using the new consumption aggregate. The details of the micro-simulation method are provided below.

To simulate the poverty and inequality effects of taxation reforms, six simple micro equations were estimated. The first three simple equations are: total income for the base scenario; total income adjusted for the pre-2011 income tax scenario; and total income adjusted for the post-2011 income tax scenario. The second three simple equations are: total consumption for the base scenario; total consumption adjusted for the pre-2020 value added tax scenario; and total consumption adjusted for the 2020 value added tax scenario. These are detailed below.

\section{Base income tax scenario:}

Total income in the base scenario (totinc) is formed of labour wage (labour), crop income (crop), livestock income (livestock), fishing income (fishing), self-employment income (selfemployment), transfer income (transfer) and other income (other). This is described below as:

totinc $=$ labour + crop + livestock + fishing + self-employment + transfer + other

\section{Pre-2011 income tax scenario:}

This scenario involves the analysis of redistribution using the pre-2011 income tax structure (see Table 9 in the appendix). The study applied the tax structure on the labour wages alone (in accounting for informality) and on both the labour wages and self-employment income (in ignoring the existence of the informal sector). Hence, the labour and self-employment variables in equation 1 above become net labour and net self-employment as described in equation 2 below:

totinc $(\mathrm{n} 1)=$ netlabour $(\mathrm{n} 1)+$ crop + livestock + fishing + netself-employment $(\mathrm{n} 1)+$ transfer + other

Where: totinc(n1) is the total income after taxes under the pre-2011 income tax structure, whereas netlabour(n1) and netself-employment(n1) are labour wage and total selfemployment income after taxes based on the pre-2011 income tax structure, respectively. 


\section{Post-2011 income tax scenario:}

This scenario involves the analysis of redistribution based on the post-2011 income tax structure (see Table 10 in the appendix). The study applied the tax structure on labour wages alone (in accounting for informality), and both the labour wages and total self-employment income (in ignoring the informality effect) as in equation 3 below:

totinc $(\mathrm{n} 2)=$ netlabour $(\mathrm{n} 2)+$ crop + livestock + fishing + netself-employment $(\mathrm{n} 2)+$ transfer + other

Where: totinc(n2) is the total income after taxes under the post-2011 income tax structure, whereas netlabour(n2) and netself-employment(n2) are labour wage and total selfemployment income after taxes based on the post-2011 income tax structure, respectively.

\section{Base VAT scenario:}

Total consumption in the base scenario (totcons) is formed of vatable items (vatable), nonvatable items (nonvatable), other non-food items (nonfood), and total food items (food). Note that this computation still gives the same value as the totalcons data in the survey, since above mentioned components form total household consumption. The total consumption for the base scenario is stated below as:

totcons $=$ vatable + nonvatable + nonfood + food

\section{Pre-2020 VAT scenario:}

This scenario involves the analysis of redistribution using the pre-2020 VAT rate of 5 per cent (2.5 per cent effective rate). The study applied the 2.5 per cent effective rate on vatable items. Hence, the vatable variable in equation 4 above becomes netvatable $e_{(n 1)}$ as described in equation 5 below:

totcons $(\mathrm{n} 1)=$ netvatable $(\mathrm{n} 1)+$ nonvatable + nonfood + food

Where: totcons(n1) is the total consumption after VAT using the pre-2020 VAT rate, whereas netvatable(n1) is vatable items after VAT proportion is subtracted. This is based on the pre2020 VAT rate.

\section{VAT scenario:}

This scenario involves the analysis of redistribution using the recent 2020 VAT rate of 7.5 per cent (3.8 per cent effective rate). The study applied the 3.8 per cent effective tax rate (ETR) on vatable items. Hence, the vatable variable in equation 4 above becomes netvatable ${ }_{(\mathrm{n} 2)}$ as described in equation 6 below:

totcons $(\mathrm{n} 2)=$ netvatable $(\mathrm{n} 2)+$ nonvatable + nonfood + food

Where: totcons(n2) is the total consumption after VAT using the 2020 VAT rate, whereas netvatable(n2) is vatable items after VAT using the 2020 VAT rate.

Further, the redistributive effect was measured through inequality (Gini coefficient) and poverty measures (poverty headcount, gap and severity). ${ }^{6}$ The Gini coefficient, a very useful measure of inequality in a distribution, calculates the difference between all income pairs in the data, and the total of all absolute differences. This total is then normalised by dividing it by the population squared times the mean income. The Gini index scales between zero and one. Zero indicates perfect equality, and one measures perfect inequality. The study also uses the Lorenz curve to present the overall income inequality. Graphically, the Lorenz curve 
consists of a vertical axis that represents cumulative income shares and a horizontal axis that measures the cumulative population. A 45-degree line in this graph represents perfect equality (similar to the Gini coefficient equals to zero). Contrariwise, if the Lorenz curve lies flat over the horizontal axis until the last person and vertical for the last person in the population, then we have the line of perfect inequality (i.e., the Gini coefficient equals one). In other words, the Lorenz curve and the Gini coefficient are inter-linked. Simply put, the Gini index is twice the area between the line of equality (45-degree line) and the Lorenz curve. The demerit of the Gini coefficient is that it only measures overall inequality within the country. However, policy makers in low- and middle-income countries are often more interested in the poorest section of the society. Consequently, this study is motivated to also simulate effects of taxes on poverty. To achieve this, the paper utilised the Foster, Greer, and Thorbecke (FGT) (1984) class of poverty (indices) measures, comprising of the poverty head count index, poverty gap index, and the poverty severity index. The poverty head count indicates the share of people that are under the poverty line. The poverty gap estimates the total poverty shortfall of the poor as compared to the line of poverty. Finally, the poverty severity indicates the squared proportional shortfall from the poverty line. This is based on how the poverty line is determined in the country. ${ }^{7}$ This basis correctly fits the current study, since the NLSS used as the source of data was initially designed to accurately measure poverty in Nigeria. ${ }^{8}$

In the redistributive effect estimates, the study also followed up on informality. It also provided results of the micro-simulation both with and without informal sector correction to ease comparison. For the redistributive effect of income taxes, the study applied the income tax table to both the formal and informal incomes, calculated their corresponding taxes, and then added them together. It then applied the added total taxes to measure their redistributive effects. Note that this was intentionally done, in order to ignore the separated effect of formal and informal incomes. Further, to make comparison possible, the study then accounted for informality by repeating the redistributive analyses using taxes computed from only the formal incomes, ignoring the informal incomes. In terms of the VAT, the study also presented comparative redistributive estimates by differently applying the statutory rates and effective rates. Of importance to note here is that the study attempts to provide a comparative descriptive analysis of the size of the formal and the informal sector, together with their corresponding average earnings, comprising proportionate mean incomes of formally employed and informally engaged individuals per household (see Table 2).

\subsection{Micro-simulation of the relief allowance structure in the 2011 PIT Act}

To shed more light on the redistributive effect of PIT, this section employs the static microsimulation technique to capture how the pre-tax income distribution changes when the legally mandated lump sum relief allowance (deductions) in the current PIT scheme is modified/regulated. This subsection aims to test the extent of change that will occur in progressivity and redistribution when lump sum relief allowance in the post-2011 PIT is regulated. Drawing on the micro-level data for each individual household, the study simulates the lump sum relief allowance regulations for four varying counterfactual scenarios.

In scenario one, the study only capped the fixed part of the relief allowance at $\$ 100,000$, without altering the variable part. In scenario two, the study capped both the variable and the fixed parts of the relief at 10 per cent and $\$ 100,000$ respectively. In scenario three, the study gave the variable part of the lump sum relief allowance to only the low-income taxpayers below a predefined income threshold, entirely excluding high-income taxpayers, and then

In Nigeria, the official poverty line is based on the 'cost of basic needs approach' referred to as the monetary value of food and non-food expenditures needed for an individual to achieve a basic level of welfare (NBS 2020). Currently, this total monetary value for Nigeria equal 137,430 Naira (NLSS 2018/2019). This value has been utilised in calculating poverty in this study.

$8 \quad$ The NLSS is the official survey that serves as the basis for measuring poverty and living standards in Nigeria. 
gave the fixed part of the relief to all taxpayers. In scenario four, the fixed component was given to all taxpayers plus the variable part. But the variable part was multiplied by a certain predetermined (fixed) amount. Hence, the variable part did not grow beyond the predetermined level. Next, the statutory tax rates and tax tables were employed to simulate the new tax liabilities and after-tax income for each individual household under the varying scenarios. Finally, the progressivity and redistributive effect were calculated using the PIT modified in line with the predesigned counterfactual scenarios. The baseline and simulated scenarios were calculated as follows:

Baseline scenario: The variable and fixed parts of the lump sum relief allowance (CRA) without cap. This is accounted for using $\mathrm{Y}_{0}-\mathrm{T}_{0}$, where $\mathrm{Y}_{0}$ is gross income and $\mathrm{T}_{0}$ refers to income tax liabilities.

Scenario one: The fixed part of the CRA is capped at $\$ 100,000$. This is accounted for as $\mathrm{Y}_{0}-\mathrm{T}_{1}$, where $\mathrm{Y}_{0}$ is gross income and $\mathrm{T}_{1}$ refers to simulated tax liabilities when only the fixed part of the relief allowance is capped at $\$ 100,000$.

Scenario two: The variable and fixed parts of the CRA are capped at 10 per cent and \#100,000 respectively. To account for this, the study uses $Y_{0}-T_{2}$, where $Y_{0}$ is gross income and $\mathrm{T}_{2}$ refers to simulated tax liabilities when variable and fixed parts of the CRA are capped at 10 per cent and $\$ 100,000$ respectively.

Scenario three: All the variable components (20 per cent +8 per cent) were provided only for income taxpayers below a predefined income threshold (\$314,000), excluding taxpayers above or equal to this threshold (see more details below). Then the fixed component ( $\$ 200,000$ ) was given to all income taxpayers. Note that the individual households above or equal to this predefined income threshold are the high-income taxpayers who do not get the variable component at all. To account for this, the study uses $\mathrm{Y}_{0}-\mathrm{T}_{3}$, where $\mathrm{Y}_{0}$ is gross income and $\mathrm{T}_{3}$ refer to simulated tax liabilities when all the variable parts are provided to only income taxpayers below the predefined income threshold and the fixed part is provided to all income taxpayers. Section 4.6.1 below provides more details on the determination of the eligibility standard.

Scenario four: This is an alternative to scenario three above. Analysis of this scenario shows that it yields results very similar to scenario three above. Consequently, the study has intentionally not disclosed its corresponding outcomes in the result section - for the sake of conciseness. ${ }^{9}$ Here, the fixed component is given to all income taxpayers plus the variable part (28 per cent) of a certain small fixed amount. That is, the variable part is multiplied by a given predetermined amount, so that its variable nature is completely constrained within a predetermined level. Here, the study fixed the certain amount to 28 per cent times the value of the predefined income threshold in scenario three. Hence, both the low- and high-income taxpayers take share in the fixed and variable relief components, but as previously mentioned the variable part of the relief is restricted from growing beyond the predefined income threshold.

\subsubsection{Defining eligibility criterion for lump sum relief allowance distribution across individual households in the middle/low-income category}

To define a threshold that will enable the proper distribution of the variable part of the lump sum relief allowance across low-income taxpayers, this study divided the income distribution into deciles (10 income groups - ranging from the top to the bottom 10 per cent). The desired threshold should enable the allocation of the variable part of the lump sum relief allowance to

The results of scenario four are available upon request. 
only low-income taxpayers from the middle to the lowest income decile, entirely excluding income taxpayers above the middle to the highest income decile. Hence, the study selected the income $(\$ 314,000)$ of least taxpayer in the top 60 per cent of the income distribution to serve as the guiding threshold. This means that any taxpayer whose income is below this threshold is within the middle (bottom 50 per cent) and the lowest (bottom 10 per cent) income category (i.e. within the lowest 50 per cent of the income distribution). Hence, the eligibility standard is that any individual household within this lowest 50 per cent of the income distribution is defined as a low-income taxpayer and automatically qualified to receive the variable part of the relief allowance. On the contrary, any individual household within the top 60 per cent (from the least household in the top 60 per cent to the number one household in the top 10 per cent) of the income distribution is defined as a high-income taxpayer and hence, entirely disqualified from receiving this variable portion of the relief allowance. Note that the fixed part of the allowance is then distributed to all income taxpayers.

The methodology described in the subsection above was then employed to calculate inequality, poverty, progressivity and redistribution indicators in line with these predesigned counterfactual scenarios.

\section{Results}

\subsection{Economic activities and earnings of the average Nigerian household}

This subsection presents the various labour activities in which Nigerian households participate, together with their corresponding annual average incomes.

Table 2 Household economic activities, with corresponding average income shares

\begin{tabular}{|l|l|l|l|l|l|}
\hline $\begin{array}{l}\text { First } \\
\text { part }\end{array}$ & \multicolumn{4}{|c|}{ Economic activities (\% of sampled households) } & \\
\hline Strata & Wage employment & Farming & Self-employment & Apprenticeship & No activity \\
\hline Nigeria & 8.61 & 33.64 & 18.22 & 2.58 & 36.91 \\
\hline Urban & 43.16 & 11.28 & 33.61 & 46.97 & 27.47 \\
\hline Rural & 56.84 & 88.72 & 64.39 & 53.03 & 72.53 \\
\hline $\begin{array}{l}\text { Second } \\
\text { part }\end{array}$ & \multicolumn{7}{|l|}{ Annual average incomes of formally and informally employed Nigeria households } & \\
\hline Nigeria & 802,127 & 73,165 & 912,863 & n/a & n/a \\
\hline Urban & 944,851 & 39,728 & $1,263,509$ & n/a & n/a \\
\hline Rural & 691,790 & 88,059 & 715,273 & n/a \\
\hline
\end{tabular}

Note: ${ }^{1}$ In the first part of the table, the results for each activity is in \% of total households in all activities in the survey.

${ }^{2}$ Urban or rural activity in the same first part of the table is in \% of total households in each corresponding activity.

${ }^{3} \mathrm{n} / \mathrm{a}=$ not available. In other words, apprenticeship earnings are not reported, and of course people with no activity have no incomes in the survey data.

${ }^{4}$ Annual average incomes in the above table are reported in 000' Nigeria Naira.

From Table 2, wage employment with about 9 per cent of the total survey sample is lowest in share of economic participation after the share of apprenticeship ${ }^{10}$ (about 3 per cent). As reported in the survey interviewer manual, this wage employment is the main wage job of the individual ${ }^{11}$ and hence excludes any other activity involving self-employment ${ }^{12}$ and any farm

10 Apprenticeship relates to individuals working with a craft or trade expert within a set period to develop their skills. This activity could be paid or unpaid.

In fact, the labour part of the survey data has reported monetary payment coming from only this main wage job.

Self-employment is defined in the survey interviewer manual to mainly involve informal activities comprising of carpentry, hairdressing, shop keeping, or making and selling of food that takes place within or outside the home, village market, roadside or in the streets. The monetary reward from self-employment is reported separately in the non-farm enterprise section of the survey data. 
or agricultural related activities. ${ }^{13}$ The current study in accounting for the informal sector has applied the graduated income tax table only on the main wage job activity. As seen in Table 2 , households temporarily in no income related activity take the largest share -37 per cent ${ }^{14}$ followed by the households involved in farming and self-employment activities with about 34 per cent and 18 per cent shares respectively. In terms of sector (urban-rural) division in the above table, farming activity reveals the largest share (89 per cent) in rural areas, followed by 'no activity' with about 73 per cent of its households in the rural areas. This high concentration in the rural areas is not surprising since farmers and individuals with no jobs are easily found in the rural part of the country. Out of the roughly 18 per cent of Nigerians in self-employment activity, the urban households take roughly 34 per cent share, whereas the rural households take about 64 per cent share. This implies that informal activities in rural areas are double the proportion in urban areas. For wage employment, revealing about 9 per cent share of total households, the urban and rural workers total 43 per cent and 56 per cent ${ }^{15}$ shares respectively. In summary, the above table uncovers a small formal sector (wage employment) size of about 9 per cent, and a total large informal sector (both farming and self-employment) size of roughly 52 per cent of the total survey sample. Notably, the current study applies the tax code on the 9 per cent formal sector ${ }^{16}$ when considering ineffective tax administration. However, to compare results and see differences in formal and informal incomes the study also applies taxes on the total sector (formal and informal) proportion of 61 per cent.

The second part of Table 2 also reveals some differences in terms of the average income shares of households between the formal and the informal sectors. Relative to the average income share ( $\$ 802,127)$ from wage employment activities (9 per cent), self-employment activities (34 per cent) generate the largest average income share (\$912,863). A similar trend is also observed in terms of urban-rural division. Self-employment activities in the urban (34 per cent) and rural (64 per cent) sectors generate the largest average income shares $(\$ 1,263,509)$ and $(\$ 715,273)$ as compared with the income shares ( $\$ 944,851)$ and ( $\$ 691,790)$ from wage activities in the urban and rural sectors respectively. These results are of no surprise following the large size of the informal sector, a total of about 52 per cent comprising both farming and self-employment. In terms of agriculture as part of the informal sector, farming activities in rural areas produce the largest average income share $(\$ 88,059)$, relative to the share $(\$ 39,728)$ generated in the urban sector. This result is also anticipated following the fact that farming activities concentrate more in the rural (about 89 per cent) than in the urban (11 per cent) part of the country. Similarly, the survey reports that urban households in farming activities produce output mainly for household consumption, as compared with rural farmers producing largely for sale, though reserving some part for household consumption.

\subsection{Equity and redistribution analysis of taxation reforms}

This subsection mainly presents the result of the incidence and the redistributive effect of taxation (PIT and VAT) reforms without and with the above proposed informal sector correction to enable comparison using the Kakwani Index and the simple static microsimulation method in the Nigeria context.

13 Mainly comprise fish farming, crop cultivation, and livestock rearing activities.

14 Within this proportion, some people normally work in any of the first three activities listed above and are temporarily absent but plan to return. Some are not engaged but actively searching, while some are either not actively searching or have applied for a particular activity and are awaiting a response.

15 The relatively large share of workers in the rural areas is of little surprise in the current day Nigeria. Due to inflated prices, workers face high costs of living in urban areas. To solve this issue, most workers with relatively low earnings prefer to live in rural areas where cost of livings (e.g. rent, food) are somewhat cheaper.

16 Note that all workers in the formal sector pay taxes in Nigeria. No one is exempted. Even the very low-income earners with no taxable income pay a minimum tax rate of 0.5 per cent in the pre-2011 scheme and 1 per cent in the current PIT scheme (see the graduated tax rules in tables 9 and 10 of the appendix). 
Table 3 Progressivity of PIT under each scenario (both national and regional estimates)

\begin{tabular}{|c|c|c|c|c|c|}
\hline Kakwani Index & Coef. & Std. Err. & t-value & Prob. & Conf. Interval \\
\hline First part & \multicolumn{5}{|c|}{ Estimates without informal sector correction } \\
\hline \multicolumn{6}{|l|}{ Pre-2011 PIT scheme } \\
\hline National & 0.1341 & 0.0109 & 12.23 & 0.000 & 0.11260 .1556 \\
\hline Urban & 0.1051 & 0.0144 & 7.29 & 0.000 & $0.0768 \quad 0.1334$ \\
\hline Rural & 0.1516 & 0.0116 & 13.11 & 0.000 & 0.12890 .1743 \\
\hline \multicolumn{6}{|l|}{ Post-2011 PIT reform } \\
\hline National & -0.0277 & 0.0176 & 1.56 & 0.116 & $-0.0622-0.0068$ \\
\hline Urban & 0.0600 & 0.0276 & 2.21 & 0.027 & 0.00680 .1151 \\
\hline Rural & -0.1163 & 0.0207 & -5.62 & 0.000 & $-0.1569-0.0756$ \\
\hline Second part & \multicolumn{5}{|c|}{ Estimates with informal sector correction } \\
\hline \multicolumn{6}{|l|}{ Pre-2011 PIT scheme } \\
\hline National & 0.1189 & 0.0483 & 2.46 & 0.014 & $0.0240 \quad 0.2138$ \\
\hline Urban & 0.0845 & 0.0726 & 1.16 & 0.245 & -0.05810 .2270 \\
\hline Rural & 0.1386 & 0.0511 & 2.71 & 0.007 & 0.03830 .2389 \\
\hline \multicolumn{6}{|l|}{ Post-2011 PIT reform } \\
\hline National & -0.3684 & 0.0300 & -12.27 & 0.000 & $-0.1498-0.2186$ \\
\hline Urban & -0.3453 & 0.0513 & -6.73 & 0.000 & $-0.4461-0.2445$ \\
\hline Rural & -0.3723 & 0.0341 & -10.92 & 0.000 & $-0.4393-0.3054$ \\
\hline
\end{tabular}

Table 3 presents the Kakwani Indices under the pre-2011 and post-2011 income tax reform scenarios, both without and with informal sector correction. According to estimates without informal sector correction in the first part of this table, the pre-2011 income tax scheme yields a positive Kakwani Index at the national $(0.1341)$, urban $(0.1051)$ and rural $(0.1516)$ levels respectively. This implies that income tax was progressive in the pre-2011 scheme at both national and regional levels. Intuitively, the poor pay less, whereas the rich pay more of their income as tax within this scheme. In contrast, the post-2011 income tax scheme reveals a negative Kakwani Index at the national level $(-0.0277)$. Although the index is positive at the urban level $(0.0600)$, it still remains negative at the rural level $(-0.1163)$. The reason for differences here could be because of scale effect. The survey data reveals that people residing in the rural area responded more to the survey relative to urban residents. Following from the negative national Kakwani Index, however, it is concluded that the income tax is regressive in the post-2011 scheme. Put differently, this is a pro-rich scheme, where the rich individual pays less, whereas the poor individual pays more of their income to the tax system.

Table 3 also presents the Kakwani Indices in the pre-2011 and post-2011 income tax schemes, but accounting for informality in the economy. The results as seen in the second part of this table show a similar trend to recorded estimates without correcting for informality but reveal differences in the size of Kakwani Indices. Here, the pre-2011 scheme yields a positive Kakwani Index at the national (0.1189), urban (0.0845), and rural level (0.1386) respectively. In terms of regional differences, the PIT after accounting for informality tends to be more progressive in rural than in urban areas. As mentioned above, these differences could be attributed to the scale effect - respondents in rural areas responding more to the survey, relative to responses recorded in urban areas. In general, the results simply imply a progressive income tax when accounting for informality. However, the sizes of the Kakwani Indices are lesser compared to estimates without correcting informality. This simply means that when informality is corrected, income tax becomes less progressive. On the contrary, the post-2011 scheme produces a negative Kakwani Index at the national (-0.3684), urban ($0.3453)$ and rural $(-0.3723)$ levels, which mainly implies a regressive income tax when informality is accounted for. However, the Kakwani Index is more negative compared to the 
estimated index without correcting informality. This simply means that when informality is taken into account, income tax becomes more regressive in Nigeria. In summary, we deduce from the above analyses that the actual income tax progressivity tends to be overestimated when ineffective tax administration is not put into consideration.

Further, the regressivity results above could be partly attributable to the fact that the current PIT tax structure does not clearly differentiate the middle (low) income from high-income earners, since virtually most middle-income earners reach a high marginal tax rate of up to 21 per cent. For instance the PIT Act provides that two individual taxpayers with total annual income of $1.6 \mathrm{~m}$ and $\$ 3.2 \mathrm{~m}$ reach a high graduated tax rate, even though the former's income amount is less than the average annual cost of living within the current day realities (inflated prices) in Nigeria. This regressivity finding is line with what was reported in Egbon and Mgbame 2015. In their anecdotal study of income tax progressivity, they found that the current PIT regime in Nigeria is regressive, i.e. the scheme is more pro-rich than it is propoor. This also follows from the fact that in this current scheme the low-income earners or workers with no taxable income still pay a tax rate of 1 per cent, which is 50 per cent higher than the minimum rate of 0.5 per cent paid by wage workers in the old tax scheme. The regressivity results could be mainly attributable to the growing debate (e.g. Avram 2017; Cano 2017) pointing to the direction that the lump sum relief allowance limits income tax progressivity, since it mainly accrues to taxpayers at the top of the income distribution. The current study confirms this by plotting the decile shares of the post-2011 PIT relief allowance in Figure 1.

\section{Figure 1 Decile shares of the post-2011 PIT consolidated relief allowance (CRA)}

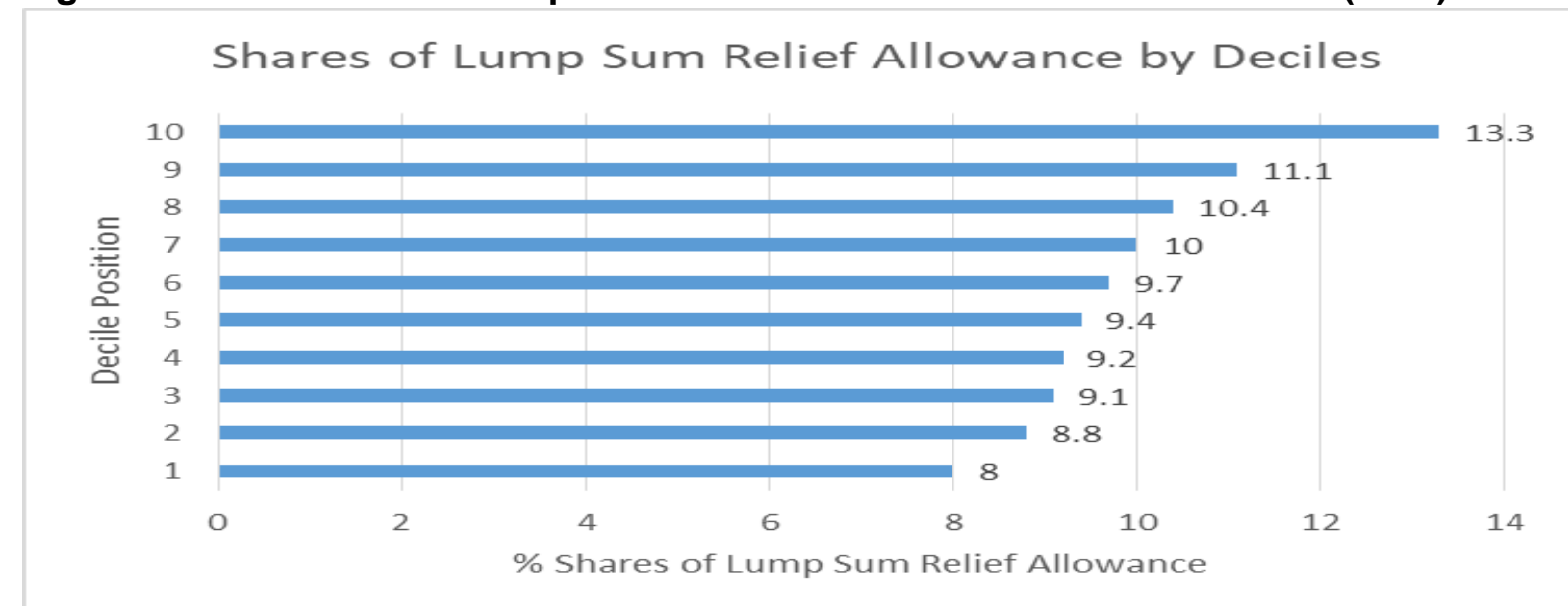

Source: Author's calculation using income adjusted for underreporting in the latest survey data.

Figure 1 shows the decile distribution of the deductible relief allowance ( $\$ 200,000$ plus 28 per cent of income) in the post-2011 PIT scheme. Bearing in mind that the highest income earners are missing in the survey, the figure above at least shows some light, that the largest proportion of the lump sum relief allowance (13.3 per cent) in the post-2011 tax scheme belongs to the top 10 per cent of taxpayers at the upper end of the distribution, while the smallest amount (8 per cent) goes to the 10 per cent at the bottom of the distribution. Indeed, this kind of distribution induces regressivity. In other words, the top 10 per cent (high-income) taxpayers have benefited the most from income tax deductions relative to the low-income taxpayers. This finding is in line with those of previous related studies (Avram 2017; Cano 2017; Inchauste and Rubil 2017), showing that taxpayers at the top of the income class benefit the most from income tax relief deductions, relative to taxpayers at the bottom of the income class. This confirms the finding in Table 3 of the regressivity of the post-2011 PIT scheme. If high-income taxpayers are able to claim the largest share of the relief allowance, then they enjoy a lower taxable income, and hence pay less income tax, relative to the lowincome taxpayers. To attempt to address this problem, the current study examines in tables 
4 and 7 some counterfactual scenarios involving the capping/regulation of the newly introduced lump sum relief allowance.

Table 4 Simulating progressivity of the post-2011 PIT relief structure (national and regional estimates) ${ }^{17}$

\begin{tabular}{|l|l|l|l|l|l|l|}
\hline \multicolumn{1}{|c|}{ Kakwani Index } & Coef. & Std. Err. & t-value & Prob. & Conf. interval \\
\hline Base scenario & \multicolumn{5}{|c|}{ Variable and fixed parts of the relief allowance (CRA) without cap } \\
\hline National & -0.3684 & 0.0300 & -12.27 & 0.000 & $-0.1498-0.2186$ \\
\hline Urban & -0.3453 & 0.0513 & -6.73 & 0.000 & $-0.4461-0.2445$ \\
\hline Rural & -0.3723 & 0.0341 & -10.92 & 0.000 & $-0.4393-0.3054$ \\
\hline Scenario one & \multicolumn{5}{|c|}{ Cap only the fixed part of the CRA at 100,000} \\
\hline National & -0.3192 & 0.0300 & -10.63 & 0.000 & $-0.3781-0.2603$ \\
\hline Urban & -0.2841 & 0.0505 & -5.63 & 0.000 & $-0.3832-0.1849$ \\
\hline Rural & -0.3362 & 0.0335 & -10.02 & 0.000 & $-0.4021-0.2704$ \\
\hline Scenario two & \multicolumn{5}{|c|}{ Cap the variable and fixed parts of the CRA at 10\% and 100,000 resp. } \\
\hline National & -0.2917 & 0.0308 & -9.49 & 0.000 & $-0.3520-0.2313$ \\
\hline Urban & -0.2526 & 0.0521 & -4.85 & 0.000 & $-0.3549-0.1503$ \\
\hline Rural & -0.3153 & 0.0334 & -9.45 & 0.000 & $-0.3809-0.2498$ \\
\hline Scenario three & Give the variable part to low-income taxpayers only, and the fixed part to all taxpayers \\
\hline National & 0.0050 & 0.0188 & 0.27 & 0.788 & -0.03190 .0420 \\
\hline Urban & 0.0059 & 0.0285 & 0.21 & 0.836 & -0.05020 .0621 \\
\hline Rural & -0.0055 & 0.0208 & -0.27 & 0.789 & -0.04640 .0353 \\
\hline
\end{tabular}

Notes: ${ }^{1}$ The base scenario is the actual situation where the variable and fixed parts of the CRA are not capped.

${ }^{2}$ In scenario one, the fixed part of the CRA is capped at 100,000 .

${ }^{3}$ In scenario two, the variable and fixed parts of the CRA are capped at $10 \%$ and 100,000 respectively.

${ }^{4}$ In scenario three, the variable part $(20 \%+8 \%)$ is only for taxpayers below a predefined income threshold, whereas the fixed part is for all taxpayers.

${ }^{5}$ As previously mentioned, the results of scenario four are very similar to that of scenario three, so that the study intentionally excluded them in Table 4 above - to dodge verbosity. But the results are available upon request.

Table 4 presents the equity results of the post-2011 PIT relief policy simulations. It is clear from this table that the Kakwani Indices of progressivity are negative in simulated scenarios one and two. This means that the PIT remains regressive, albeit much less relative to that of the base scenario. However, a striking opposite result is observed in scenario three where the variable part of the relief allowance is given to only the low-income taxpayers below a predefined income threshold of $\$ 314,000$, entirely excluding high-income taxpayers above or equal to the threshold (see threshold definition above). In this scenario three, the Kakwani Index becomes positive across national and subnational levels (excluding the rural region with a little difference - attributable mainly to sample scale effect). The interpretation of scenarios one and two is an obvious decline in regressivity, relative to the base scenario. However, the general interpretation of scenario three is an obvious progressivity effect, relative to scenarios one and two and base scenario. As seen in Table 4, there is a reduction in the Kakwani Index at the national level from -0.3684 in the base scenario to -0.3192 in scenario one, and further down to -0.2917 in scenario two. On the contrary, there is a clearly national progressivity effect $(0.0050)$ in scenario three. Notably, the declining regressivity trend in scenario one and two is also observed at the subnational levels, both urban and rural. In terms of scenario three, the progressivity effect is also similar across the national and subnational levels (though a little different in the rural region - attributable to scale effect). To make things clear, the urban positive effect $(0.0059)$ is just enough to cancel out the rural negative effect $(-0.0055)$. So the overall result in scenario three is a clear

Note that the simulation results presented in this table 4 and table 7 below are only for the case of 'corrected informality'. The simulation results 'without informality correction' are intentionally not presented, mainly to avoid ambiguity. In this subsection, the focus is more on results with corrected ineffective tax administration. Notably, the results presented here are still in similar direction with results - 'without informal sector correction'. The latter results are available upon request. 
progressivity effect, relative to the base scenario across the country. The results of the simulated scenarios one and two simply imply that progressivity will improve (albeit through a declining regressivity) if the lump sum relief allowance in the post-2011 PIT Act is capped. Contrariwise, the result of the simulated scenario three simply implies that progressivity will improve even more through a positive Kakwani Index, relative to scenarios one and two, if the variable part of the lump sum relief allowance is provided to only low-income taxpayers below a predefined income threshold ( $\$ 314,000)$, with the high-income taxpayers entirely excluded. Hence, for equity reasons, it is crucial that the variable part of the lump sum tax relief allowance is provided only for low-income taxpayers, while the fixed part can go to all taxpayers. Indeed, these findings are similar to the outcomes of previous works, showing that the distributional consequence of tax relief allowances are generally not progressive (e.g. Avram 2017), but that these tax deductions with proper restriction help to engender progressivity on the distribution of income (e.g. Farfan-Portet, Hindricks and Lorant 2008).

Table 5 Progressivity of VAT under each scenario (both national and regional estimates)

\begin{tabular}{|c|c|c|c|c|c|}
\hline Kakwani Index & Coef. & Std. Err. & t-value & Prob. & Conf. interval \\
\hline First part & \multicolumn{5}{|c|}{ Estimates without informal sector correction } \\
\hline Pre-2020 scheme (5\% VAT) & & & & & \\
\hline National & -0.3887 & 0.0098 & -39.54 & 0.000 & $-0.4080 \quad-0.3694$ \\
\hline Urban & -0.3577 & 0.0148 & -24.17 & 0.000 & $-0.3868-0.3287$ \\
\hline Rural & -0.3755 & 0.0094 & -40.08 & 0.000 & $-0.3939-0.3571$ \\
\hline \multicolumn{6}{|l|}{2020 reform (7.5\% VAT) } \\
\hline National & -0.3887 & 0.0098 & -39.54 & 0.000 & $-0.4080--0.3694$ \\
\hline Urban & -0.3577 & 0.0148 & -24.17 & 0.000 & $-0.3868-0.3287$ \\
\hline Rural & -0.3755 & 0.0094 & -40.08 & 0.000 & $-0.3939-0.3571$ \\
\hline Second part & \multicolumn{5}{|c|}{ Estimates with informal sector correction } \\
\hline \multicolumn{6}{|l|}{ Pre-2020 scheme (2.5\% VAT) } \\
\hline National & -0.3887 & 0.0098 & -39.54 & 0.000 & $-0.4080-0.3694$ \\
\hline Urban & -0.3577 & 0.0148 & -24.17 & 0.000 & $-0.3868 \quad-0.3287$ \\
\hline Rural & -0.3755 & 0.0094 & -40.08 & 0.000 & $\begin{array}{ll}-0.3939 & -0.3571\end{array}$ \\
\hline \multicolumn{6}{|l|}{2020 reform (3.8\% VAT) } \\
\hline National & -0.3887 & 0.0098 & -39.54 & 0.000 & $-0.4080 \quad-0.3694$ \\
\hline Urban & -0.3577 & 0.0148 & -24.17 & 0.000 & $\begin{array}{ll}-0.3868 & -0.3287\end{array}$ \\
\hline Rural & -0.3755 & 0.0094 & -40.08 & 0.000 & $-0.3939-0.3571$ \\
\hline
\end{tabular}

Table 5 reports the Kakwani Indices under the pre-2020 and current VAT reform scenarios, both without and with informal sector correction. According to estimates without informal sector correction in the first part of Table 5, the pre-2020 scheme ${ }^{18}$ yields a negative Kakwani Index at the national $(-0.3887)$ urban $(-0.3577)$ and rural $(-0.3755)$ levels. Regionally, the VAT tends to be more regressive in the rural relative to the urban area. Hence, aside from the scale effect mentioned above, this result could also be attributed to people in rural regions consuming more vatable items, compared to the wealthy in urban regions consuming luxuries with little or no VAT. But in general the results suggest that VAT was regressive in the pre-2020 scheme. In other words, the rich pay less whereas the poor pay more VAT. Similarly, the 2020 scheme ${ }^{19}$ reveals a negative Kakwani Index across national (-0.3887), and regional levels. This implies a regressive VAT in the post-2020 scheme. This further suggests a pro-rich scheme, where the rich individual pays less, whereas the poor pays more VAT.

\footnotetext{
18 In the pre-2020 scheme the VAT was a 5 per cent flat rate.

19 In the 2020 scheme, i.e. currently, the VAT is a 7.5 per cent flat rate.
} 
Table 5 also presents the Kakwani Indices in the pre-2020 and 2020 VAT schemes, but in consideration of the informal sector. ${ }^{20}$ The results in the second part of this table also show identical trends and size of Kakwani Indices to estimates without correcting for informality. The Kakwani Indices after correcting for informality were also found to be negative both at the national and regional levels. Thus, we reach the conclusion that the VAT schemes taking account of informality are also regressive - pro-rich in nature. In fact, this simply means that correcting for informality by applying 2.5 per cent and 3.8 per cent effective VAT rates ${ }^{21}$ to vatable items for the pre and post-2020 schemes leaves the regressive size of VAT unchanged. These results could be partly attributed to the fact that the variations in statutory and effective VAT rates ${ }^{22}$ may not be sizeable enough to make significant changes to the reported Kakwani Indices. More specifically, in terms of the results of similar regressive sizes of VAT variables across the schemes. The major reason attributable to these results is the fact that the household's VAT proportionate contribution to the total tax payment yields the same value regardless of the differentiated VAT rates (as figured out from the survey data). Note that the monetary amount contributed by the household changes at differentiated rates, but the percentage contribution to the aggregate tax payment remains the same even at differentiated rates (as crosschecked from the data). The Kakwani method does not directly use the monetary tax amount contributed by the household, but indirectly employs the household's percentage share of the aggregate tax payment in the calculation of the progressivity/regressivity index (Kakwani 1977; O'Donnell, Van Doorslaer, Wagstaff and Lindelow 2008). From the survey data, for instance, the first household contributes $\$ 1,500$ to aggregate tax payment of $23,011,184$ at a 5 per cent VAT rate. This household's share in the aggregate tax payment $\$ 1,500$ divided by $\$ 23,011,184$ yields a proportion of 0.007 per cent. As observed from the data, if the VAT is increased to 7.5 per cent, the contribution of the first household rises to $\$ 2,250$, while aggregate tax payment rises to $\$ 34,516,776$. This means the share of the household of the aggregate tax, i.e. $\$ 2,250$ divided by $\$ 34,516,776$ at a differentiated VAT rate of 7.5 per cent, remains the same 0.007 per cent just as when the rate was 5 per cent.

In summary, the household contributes 0.007 per cent $(\$ 1,500)$ to the aggregate tax payment when the VAT rate is 5 per cent and also contributes the same percentage of 0.007 per cent $(\$ 2,250)$ when the VAT rate is changed to 7.5 per cent. From this illustration, it is clear that the tax monetary amount changes at differentiated rates, but the per cent share contribution to the aggregate amount does not differ. The Kakwani method's calculation of a progressivity/regressivity index is not based on a differentiated absolute tax amount $(\$ 1,500$ or $\$ 2,250$ ) but based on this household's undifferentiated per cent share contribution $(0.007$ per cent) to the aggregate tax payment (as observed from the Kakwani Index formula). Further, the results in Table 5 are supported with what was found in previous similar studies (Decoster and Verbina 2003; Sivashankar et al. 2017). Just as seen in Table 5, Sivashankar et al. 2017 in their work on incidence of value added taxation on inequality revealed that different VAT rates of 11 per cent and 15 per cent analysed for different policy reforms of 2011 and 2016 produced the same Kakwani Index of progressivity of 0.181 for 11 per cent and 0.181 for 15 per cent. Their results are also similar when split between the urban and

$20 \quad$ Informality was accounted for by using effective VAT rates instead of the statutory rates.

21 In line with previous related literature, the effective VAT rate (ETR) was computed using macro VAT revenue and consumption data. The ETR for the pre-2020 scheme was calculated as 2.5 per cent. Notably, the current study has utilised available and more detailed macro (i.e. 2018) data for the pre-2020 ETR calculation. Currently, the Nigeria National Bureau of Statistics has not released detailed macro consumption data for the 2020 period. Hence, the calculation of the 2020 ETR to reflect the recent 50 per cent increase in VAT rate becomes very difficult. To try to solve this issue, the current study assumes that for the 2020 period, the pre-2020 ETR rose by 50 per cent, yielding a 3.8 per cent ETR. Reasonably, this assumption is based on the 50 per cent increase in the pre-2020 statutory rate.

22 For instance, in the pre-2020 scheme, the statutory VAT rate is 5 per cent, whereas the calculated effective rate for the same period is only 2.5 per cent. Also, for the 2020 scheme, the statutory rate is 7.5 per cent (i.e. a 50 per cent increase on the previous scheme), and the corresponding effective rate is computed as a 50 per cent increase on the previous effective rate (i.e. 3.8 per cent). 
rural areas. Specifically, the urban results yielded the same index of 0.187 in both the 2011 and 2016 reform periods while the rural results yielded the same index of 0.173 in both the 2011 and 2016 reform periods. They concluded that VAT revisions made no significant change on inequality and tax incidence in Sri Lanka.

Table 6 Estimated effects of PIT under each scenario with respect to the base scenario (both national and regional estimates)

\begin{tabular}{|c|c|c|c|c|c|}
\hline & 0 & 1 & $\mathbf{A}$ & 2 & B \\
\hline & Base & Pre-2011 PIT & Actual effect & Post-2011 PIT & Actual effect \\
\hline First part & \multicolumn{5}{|c|}{ Estimates without informal sector correction } \\
\hline \multicolumn{6}{|l|}{ National estimates } \\
\hline \multicolumn{6}{|l|}{ Inequality indicator } \\
\hline Gini coefficient & 0.3895 & 0.3737 & -0.016 & 0.3869 & -0.003 \\
\hline \multicolumn{6}{|l|}{ Poverty headcount } \\
\hline Pov 0 (\%) & 41.83 & 46.22 & 4.39 & 42.24 & 0.41 \\
\hline \multicolumn{6}{|l|}{ Poverty gap } \\
\hline Pov 1 (\%) & 17.49 & 19.06 & 1.57 & 17.68 & 0.19 \\
\hline \multicolumn{6}{|l|}{ Poverty severity } \\
\hline Pov $2(\%)$ & 10.79 & 11.54 & 0.75 & 10.89 & 0.10 \\
\hline \multicolumn{6}{|l|}{ Urban estimates } \\
\hline \multicolumn{6}{|l|}{ Inequality indicator } \\
\hline Gini coefficient & 0.3614 & 0.3478 & -0.014 & 0.3571 & -0.004 \\
\hline \multicolumn{6}{|l|}{ Poverty headcount } \\
\hline Pov 0 (\%) & 23.08 & 26.70 & 3.62 & 23.40 & 0.32 \\
\hline \multicolumn{6}{|l|}{ Poverty gap } \\
\hline Pov 1 (\%) & 10.21 & 11.17 & 0.96 & 10.31 & 0.10 \\
\hline \multicolumn{6}{|l|}{ Poverty severity } \\
\hline Pov 2 (\%) & 07.45 & 07.81 & 0.36 & 07.49 & 0.04 \\
\hline \multicolumn{6}{|l|}{ Rural estimates } \\
\hline \multicolumn{6}{|l|}{ Inequality indicator } \\
\hline Gini coefficient & 0.3763 & 0.3606 & -0.016 & 0.3747 & -0.002 \\
\hline \multicolumn{6}{|l|}{ Poverty headcount } \\
\hline Pov 0 (\%) & 50.18 & 54.91 & 4.73 & 50.63 & 0.45 \\
\hline \multicolumn{6}{|l|}{ Poverty gap } \\
\hline Pov 1 (\%) & 20.74 & 22.58 & 1.84 & 20.97 & 0.23 \\
\hline \multicolumn{6}{|l|}{ Poverty severity } \\
\hline \multirow[t]{2}{*}{ Pov 2 (\%) } & 12.28 & 13.21 & 0.93 & 12.41 & 0.13 \\
\hline & \multicolumn{5}{|c|}{ Estimates with informal sector correction } \\
\hline \multicolumn{6}{|l|}{ National estimates } \\
\hline \multicolumn{6}{|l|}{ Inequality indicator } \\
\hline Gini coefficient & 0.3895 & 0.3888 & -0.001 & 0.3894 & -0.000 \\
\hline \multicolumn{6}{|l|}{ Poverty headcount } \\
\hline Pov 0 (\%) & 41.83 & 42.04 & 0.21 & 41.89 & 0.06 \\
\hline \multicolumn{6}{|l|}{ Poverty gap } \\
\hline Pov 1 (\%) & 17.49 & 17.58 & 0.09 & 17.51 & 0.02 \\
\hline \multicolumn{6}{|l|}{ Poverty severity } \\
\hline Pov 2 (\%) & 10.79 & 10.83 & 0.04 & 10.80 & 0.01 \\
\hline \multicolumn{6}{|l|}{ Urban estimates } \\
\hline \multicolumn{6}{|l|}{ Inequality indicator } \\
\hline Gini coefficient & 0.3614 & 0.3610 & -0.00 & 0.3613 & -0.00 \\
\hline
\end{tabular}




\begin{tabular}{|c|c|c|c|c|c|}
\hline \multicolumn{6}{|c|}{ Poverty headcount } \\
\hline Pov 0 (\%) & 23.08 & 23.30 & 0.22 & 23.13 & 0.05 \\
\hline \multicolumn{6}{|l|}{ Poverty gap } \\
\hline Pov 1 (\%) & 10.21 & 10.27 & 0.06 & 10.22 & 0.01 \\
\hline \multicolumn{6}{|c|}{ Poverty severity } \\
\hline Pov 2 (\%) & 07.45 & 07.47 & 0.02 & 07.45 & 0.00 \\
\hline \multicolumn{6}{|l|}{ Rural estimates } \\
\hline \multicolumn{6}{|c|}{ Inequality indicator } \\
\hline Gini coefficient & 0.3763 & 0.3755 & -0.00 & 0.3762 & -0.00 \\
\hline \multicolumn{6}{|c|}{ Poverty headcount } \\
\hline Pov 0 (\%) & 50.18 & 50.39 & 0.21 & 50.24 & 0.06 \\
\hline \multicolumn{6}{|l|}{ Poverty gap } \\
\hline Pov 1 (\%) & 20.74 & 20.84 & 0.10 & 20.76 & 0.02 \\
\hline \multicolumn{6}{|c|}{ Poverty severity } \\
\hline Pov 2 (\%) & 12.28 & 12.33 & 0.05 & 12.29 & 0.01 \\
\hline
\end{tabular}

The first part of Table 6 reveals results on the redistributive effect of income tax based on various reform scenarios, but without correcting for informality at both national and regional levels. In this table, the redistributive effect of income tax on the Gini coefficient and each poverty level is reported with respect to the base scenario (i.e. before taxes) shown in column 0 . Column $A$ in the above table reveals the actual redistributive effect of the pre-2011 tax scheme. According to the simulation result in this column, the pre-2011 tax scheme reduced inequality by 0.016 points. On the contrary, poverty headcount rose by roughly 4.4 per cent, implying that the scheme moved a considerable number of Nigerians below the poverty line. A similar trend could also be observed of the results uncovering the effect of income tax on the poverty gap and poverty severity. These results do not differ significantly when compared with the results found at the regional level. In the urban and rural regions, the pre-2011 tax scheme reduced inequality by 0.014 and 0.016 Gini points respectively. On the other hand, the poverty headcount increased in the urban and rural regions by 3.62 per cent and 4.73 per cent respectively. But some little differences exist, with income tax increasing poverty more in the rural than in the urban regions. This regional difference, though not large, is not surprising since the rural region contains more poor households, with an estimated high poverty level of about 50.2 per cent as seen in column 0 of Table 6 . On the whole, however, the increased poverty is possibly due to the old structure of the 1993/98 Nigeria PIT tax laws. In the old PIT scheme, poor individuals with no taxable income were still taxed at the rate of 0.5 per cent. This implies that poor Nigerians were still obliged to pay income taxes - a result in agreement with the conclusion reached in the anecdotal work of Osakwe (1999).

Column B of Table 6 reports the actual redistributive effect of the post-2011 income tax scheme. This current scheme produces a negligible income redistributive effect in terms of reduction in the Gini coefficient across national and regional levels. These results are confirmed using the Lorenz curves shown in Figure 2 of the appendix. In this figure, the Lorenz curves lie quite on top of each other under the considered scenarios, implying an insignificant income redistributive effect. ${ }^{23}$ Further, as can be seen in column $B$, the poverty headcount does not decrease but the recorded increases at the national ( 0.4 per cent), urban ( 0.3 per cent) and rural ( 0.4 per cent) levels are quite less than what were observed in the previous scheme at the national (4.4 per cent), urban (3.6 per cent) and rural (4.7 per cent)

23 Note that the income redistributive effect in the post-2011 scheme is more insignificant than that of the pre-2011 scheme, though not clearly shown by the Lorenz curves. However, the curves are presented as only supports, bearing in mind that Lorenz and Concentration curves are not adequate for convenient comparison (O'Donnell et al. 2008), relative to clear indices and estimates, already presented above. 
levels. The results of the poverty gap and severity also follow an identical trend, as seen in Table 6.

The second part of Table 6 also presents these results after accounting for the informal sector (i.e. by excluding informal earnings). As seen in column A, the pre-2011 scheme reduced inequality by a lesser point at the national $(0.001)$, urban $(0.00)$ and rural $(0.00)$ levels compared to the points recorded without correcting for the informal sector. This implies that excluding informal sector workers from the income tax bracket leads to a more negligible change in the Gini coefficient. ${ }^{24} \mathrm{~A}$ similar trend can be seen in the change in poverty headcount by only 0.21 per cent, 0.22 per cent and 0.21 per cent in national, urban and rural regions respectively compared to what was seen (4.4 per cent, 3.6 per cent and 4.7 per cent) at these levels when we fail to correct for the informal sector. Further, the redistributive effect of the post-2011 income tax scheme corrected for ineffective tax administration (i.e. by excluding the informal sector participation) reveals an identical trend. As seen in column B, the post-2011 scheme reduced the Gini coefficient by only 0.0 per cent at national, urban and rural levels, and marginally increased poverty to roughly 0.06 per cent at the three levels mentioned above. In general, the study partly attributes this negligible redistributive effect (inequality reduction) to the lump sum tax relief (i.e. the consolidated relief allowance) introduced in the post-2011 tax scheme, which has favoured the high-income more than the low-income taxpayers (see Figure 1). This finding is in line with that of previous related studies (Avram 2017; Cano 2017; Inchauste and Rubil 2017), showing that the relief allowance tends to undermine the redistributive capacity of the income tax, since it mainly concentrates at the top of the income distribution. To attempt to address this issue, the study conducted some counterfactual simulations, involving the regulation of the post-2011 lump sum relief allowance, to see their effect on inequality and poverty: see Table 7.

24 This confirms the above argument in the method subsection that the inclusion of the un-taxed informal sector workers in the analyses may overestimate the redistributive effect of the income tax. 
Table 7 Simulating redistributive effects of the post-2011 PIT relief structure (national and regional estimates)

\begin{tabular}{|c|c|c|c|c|c|c|c|c|}
\hline & 0 & A & 1 & B & 2 & C & 3 & D \\
\hline & $\begin{array}{l}\text { Base } \\
\text { scenario }\end{array}$ & $\begin{array}{l}\text { Actual } \\
\text { effect }\end{array}$ & $\begin{array}{l}\text { Scenario } \\
\text { one }\end{array}$ & $\begin{array}{l}\text { Actual } \\
\text { effect }\end{array}$ & $\begin{array}{l}\text { Scenario } \\
\text { two }\end{array}$ & $\begin{array}{l}\text { Actual } \\
\text { effect }\end{array}$ & $\begin{array}{l}\text { Scenario } \\
\text { three }\end{array}$ & $\begin{array}{l}\text { Actual } \\
\text { effect }\end{array}$ \\
\hline \multicolumn{9}{|c|}{ National estimates } \\
\hline \multicolumn{9}{|l|}{$\begin{array}{l}\text { Inequality } \\
\text { indicator }\end{array}$} \\
\hline Gini coefficient & 0.3895 & -0.0000 & 0.3893 & -0.0002 & 0.3892 & -0.0003 & 0.3842 & -0.0053 \\
\hline \multicolumn{9}{|l|}{$\begin{array}{l}\text { Poverty } \\
\text { headcount }\end{array}$} \\
\hline Pov 0 (\%) & 41.89 & 0.06 & 41.89 & 0.06 & 41.87 & 0.04 & 39.89 & -2.00 \\
\hline \multicolumn{9}{|l|}{ Poverty gap } \\
\hline Pov 1 (\%) & 17.51 & 0.02 & 17.51 & 0.02 & 17.51 & 0.02 & 13.45 & -4.06 \\
\hline \multicolumn{9}{|l|}{$\begin{array}{l}\text { Poverty } \\
\text { severity }\end{array}$} \\
\hline Pov 2 (\%) & 10.80 & 0.01 & 10.80 & 0.01 & 10.80 & 0.01 & 06.28 & -4.52 \\
\hline \multicolumn{9}{|c|}{ Urban estimates } \\
\hline \multicolumn{9}{|l|}{$\begin{array}{l}\text { Inequality } \\
\text { indicator }\end{array}$} \\
\hline Gini coefficient & 0.3613 & -0.0000 & 0.3611 & -0.0003 & 0.3610 & -0.0004 & 0.3386 & -0.0227 \\
\hline \multicolumn{9}{|l|}{$\begin{array}{l}\text { Poverty } \\
\text { headcount }\end{array}$} \\
\hline Pov 0 (\%) & 23.13 & 0.05 & 23.13 & 0.05 & 23.13 & 0.05 & 19.21 & -3.92 \\
\hline \multicolumn{9}{|l|}{ Poverty gap } \\
\hline Pov 1 (\%) & 10.22 & 0.01 & 10.21 & 0.00 & 10.21 & 0.00 & 5.01 & -5.21 \\
\hline \multicolumn{9}{|l|}{$\begin{array}{l}\text { Poverty } \\
\text { severity }\end{array}$} \\
\hline Pov 2 (\%) & 07.45 & 0.00 & 07.45 & 0.00 & 07.45 & 0.00 & 2.04 & -5.41 \\
\hline \multicolumn{9}{|c|}{ Rural estimates } \\
\hline \multicolumn{9}{|l|}{$\begin{array}{l}\text { Inequality } \\
\text { indicator }\end{array}$} \\
\hline Gini coefficient & 0.3762 & -0.0000 & 0.3761 & -0.0002 & 0.3760 & -0.0002 & 0.3838 & 0.0076 \\
\hline \multicolumn{9}{|l|}{$\begin{array}{l}\text { Poverty } \\
\text { headcount }\end{array}$} \\
\hline Pov 0 (\%) & 50.24 & 0.06 & 50.23 & 0.05 & 50.21 & 0.04 & 48.85 & -1.39 \\
\hline \multicolumn{9}{|l|}{ Poverty gap } \\
\hline Pov 1 (\%) & 20.76 & 0.02 & 20.75 & 0.01 & 20.75 & 0.01 & 17.11 & -3.65 \\
\hline \multicolumn{9}{|l|}{$\begin{array}{l}\text { Poverty } \\
\text { severity }\end{array}$} \\
\hline Pov 2 (\%) & 12.29 & 0.01 & 12.29 & 0.01 & 12.29 & 0.01 & 8.11 & -4.18 \\
\hline
\end{tabular}

Note: ${ }^{1}$ The base scenario is the actual situation where the variable and fixed parts of the relief allowance (CRA) are not capped.

${ }^{2}$ In scenario one, the fixed part of the CRA is capped at 100,000 .

${ }^{3}$ In scenario two, the variable and fixed parts of the CRA are capped at $10 \%$ and $\$ 100,000$ respectively.

${ }^{4}$ In scenario three, the variable part $(20 \%+8 \%)$ is only for income taxpayers below a predefined income threshold, whereas the fixed part is for all income taxpayers.

${ }^{5}$ Note again that the results of scenario four are intentionally not reported, since they are very similar to those of scenario three.

Table 7 presents the redistribution results of the post-2011 PIT relief policy simulations. The results are similar and confirm the outcomes of the equity implications of the relief allowance presented in Table 4. Table 7 reveals an increased redistributive effect of the income tax with regulated relief structure in simulated scenarios one and two. However, when high-income taxpayers above or equal to a predefined income threshold are entirely excluded from sharing in the variable part of the lump sum relief in simulated scenario three, a large increased redistributive effect is observed, relative to those of scenarios one and two. As seen from Table 7, inequality at the national level is declined by some amount, though marginal in scenarios one and two. Contrariwise, inequality is declined by a larger amount in 
scenario three where the variable part of the relief allowance is provided only to the lowincome taxpayers, entirely excluding the high-income taxpayers. While the decline in inequality in the base scenario is just -0.0000 , the decline in scenarios one and two is at least relatively higher, by -0.0002 and -0.0003 respectively. However, the decline in scenario three is relatively much bigger, -0.0053 . Intuitively, the Gini index is more negative in scenarios one and two, relative to the base scenario. But in scenario three it is much more negative compared to the base scenario and scenarios one and two. More so, this trend of declining inequality at the national level is similar to what is observed across the subnational (urban and rural) levels in both scenarios one and two. In scenario three, the large effect of declining inequality at the national level is also similar to that observed at the subnational level, except the rural region (although as mentioned above attributable to the scale effect). Just to be clear, the large inequality decline $(-0.0227)$ observed in the urban region is more than enough to cancel out the marginal positive effect $(0.0076)$ in the rural region. So that in general a huge declining inequality is observed across the country in simulated scenario three where relatively high-income taxpayers do not take any share in the variable part of the lump sum relief allowance. In terms of poverty, a similar trend is also noticed. The national poverty level is declined from 0.06 in the base scenario to 0.04 in scenario two. On the contrary, a marked poverty reduction effect is seen in scenario three. In scenario three, poverty is largely declined down to -2.00 , relative to the marginal decline observed in scenario two. While the urban poverty headcount shows little or no change across scenarios one and two, the rural poverty headcount is declined from 0.06 in the base scenario to 0.04 in scenario two. However, a relatively marked difference is seen for the urban and rural poverty reduction effects in scenario three. In scenario three, poverty level is largely reduced to -3.92 and -1.39 in the urban and rural areas respectively. The results of the simulated scenarios one and two simply mean that redistribution will enhance (through declining inequality and poverty levels) if the relief allowance in the post-2011 PIT Act is capped or modified. However, a much bigger redistribution is seen in scenario three. In particular, if an eligibility criterion is used to exclude high-income taxpayers from sharing in the variable part of the relief allowance, by providing it to only low-income taxpayers below a predefined income threshold, inequality and poverty are markedly reduced. Hence, it is important to properly regulate the variable part of the tax relief allowance, to significantly improve the welfare of the poor people. These findings confirm outcomes in previous related studies (e.g. Avram 2017), revealing that the regulation of relief allowance helps to boost the redistributive capacity of the income tax policy instrument. 
Table 8 Estimated effects of VAT under each scenario with respect to the base scenario (both national and regional estimates)

\begin{tabular}{|c|c|c|c|c|c|}
\hline & 0 & 1 & $\mathbf{A}$ & 2 & B \\
\hline & Base & Pre-2020 VAT & Actual effect & 2020 VAT & Actual effect \\
\hline First part & \multicolumn{5}{|c|}{ Estimates without informal sector correction } \\
\hline \multicolumn{6}{|l|}{ National estimates } \\
\hline \multicolumn{6}{|l|}{ Inequality indicator } \\
\hline Gini coefficient & 0.3892 & 0.3911 & 0.002 & 0.3921 & 0.003 \\
\hline \multicolumn{6}{|l|}{ Poverty headcount } \\
\hline Pov 0 (\%) & 38.81 & 39.21 & 0.40 & 39.43 & 0.62 \\
\hline \multicolumn{6}{|l|}{ Poverty gap } \\
\hline Pov $1(\%)$ & 13.11 & 13.41 & 0.30 & 13.56 & 0.45 \\
\hline \multicolumn{6}{|l|}{ Poverty severity } \\
\hline Pov 2 (\%) & 06.00 & 06.21 & 0.21 & 06.32 & 0.32 \\
\hline \multicolumn{6}{|l|}{ Urban estimates } \\
\hline \multicolumn{6}{|l|}{ Inequality indicator } \\
\hline Gini coefficient & 0.3603 & 0.3615 & 0.00 & 0.3622 & 0.00 \\
\hline \multicolumn{6}{|l|}{ Poverty headcount } \\
\hline Pov 0 (\%) & 18.36 & 18.68 & 0.32 & 18.90 & 0.54 \\
\hline \multicolumn{6}{|l|}{ Poverty gap } \\
\hline Pov 1 (\%) & 04.76 & 04.90 & 0.14 & 04.98 & 0.22 \\
\hline \multicolumn{6}{|l|}{ Poverty severity } \\
\hline Pov 2 (\%) & 01.84 & 01.91 & 0.07 & 01.95 & 0.11 \\
\hline \multicolumn{6}{|l|}{ Rural estimates } \\
\hline \multicolumn{6}{|l|}{ Inequality indicator } \\
\hline Gini coefficient & 0.3763 & 0.3785 & 0.00 & 0.3796 & 0.00 \\
\hline \multicolumn{6}{|l|}{ Poverty headcount } \\
\hline Pov 0 (\%) & 47.92 & 48.35 & 0.43 & 48.57 & 0.65 \\
\hline \multicolumn{6}{|l|}{ Poverty gap } \\
\hline Pov 1 (\%) & 16.83 & 17.20 & 0.37 & 17.39 & 0.56 \\
\hline \multicolumn{6}{|l|}{ Poverty severity } \\
\hline Pov 2 (\%) & 07.86 & 08.13 & 0.27 & 08.27 & 0.41 \\
\hline Second part & \multicolumn{5}{|c|}{ Estimates with informal sector correction } \\
\hline \multicolumn{6}{|l|}{ National estimates } \\
\hline \multicolumn{6}{|l|}{ Inequality indicator } \\
\hline Gini coefficient & 0.3892 & 0.3901 & 0.001 & 0.3906 & 0.001 \\
\hline \multicolumn{6}{|l|}{ Poverty headcount } \\
\hline Pov 0 (\%) & 38.81 & 39.06 & 0.25 & 39.15 & 0.34 \\
\hline \multicolumn{6}{|l|}{ Poverty gap } \\
\hline Pov $1(\%)$ & 13.11 & 13.26 & 0.15 & 13.33 & 0.22 \\
\hline \multicolumn{6}{|l|}{ Poverty severity } \\
\hline Pov $2(\%)$ & 06.00 & 06.10 & 0.10 & 06.16 & 0.16 \\
\hline Urban estimates & & & & & \\
\hline Inequality indicator & & & & & \\
\hline Gini coefficient & 0.3602 & 0.3609 & 0.00 & 0.3612 & 0.00 \\
\hline Poverty headcount & & & & & \\
\hline Pov $0(\%)$ & 18.36 & 18.51 & 0.15 & 18.60 & 0.24 \\
\hline Poverty gap & & & & & \\
\hline Pov 1 (\%) & 04.76 & 04.83 & 0.07 & 04.87 & 0.11 \\
\hline Poverty severity & & & & & \\
\hline
\end{tabular}




\begin{tabular}{|c|c|c|c|c|c|}
\hline Pov $2(\%)$ & 01.84 & 01.88 & 0.04 & 01.89 & 0.05 \\
\hline \multicolumn{6}{|l|}{ Rural estimates } \\
\hline \multicolumn{6}{|c|}{ Inequality indicator } \\
\hline Gini coefficient & 0.3763 & 0.3774 & 0.00 & 0.3779 & 0.00 \\
\hline \multicolumn{6}{|c|}{ Poverty headcount } \\
\hline Pov 0 (\%) & 47.92 & 48.22 & 0.30 & 48.31 & 0.39 \\
\hline \multicolumn{6}{|l|}{ Poverty gap } \\
\hline Pov 1 (\%) & 16.83 & 17.01 & 0.18 & 17.11 & 0.28 \\
\hline \multicolumn{6}{|c|}{ Poverty severity } \\
\hline Pov 2 (\%) & 07.86 & 07.99 & 0.13 & 08.06 & 0.20 \\
\hline
\end{tabular}

We now shift attention to the redistributive effect of VAT, as reported in Table 8. Estimates in the first part of the table are without informal sector correction, whereas estimates in the second part are with informal sector correction. In this table, the redistributive effect of VAT on the Gini coefficient and each poverty level is reported with respect to the base scenario (i.e. before the payment of VAT). Column A of the first part of the table shows the actual redistributive effect of the pre-2020 VAT scheme. Contrary to the redistributive effect of PIT on income inequality, the simulation result in this column shows that the pre-2020 VAT scheme increased inequality, though by only 0.002 points at the national level. The effects at the urban (0.00), and rural $(0.00)$ levels are similar and very negligible. This opposing result of the PIT and VAT effects on inequality could be attributable to the regressive nature of VAT (as the same rate is applicable to both the rich and the poor) in Nigeria, as reported in Table 5 . In the same direction, poverty headcount rose by roughly 0.4 per cent, 0.3 per cent and 0.4 per cent at national, urban and rural levels respectively. This implies that the VAT scheme also moved some Nigerians below the poverty line, though by a small margin as compared to the proportions (4.4 per cent, 3.6 per cent and 4.7 per cent triggered by PIT at the national, urban and rural levels respectively. The observed increase in poverty due to VAT is also linkable to its regressive nature and probably to the fact that more low-income individuals consume vatable goods and still pay the same flat rate as high-income individuals. Notably, the result of a negligible increase in inequality due to VAT is consistent with previous related works in middle-income countries, e.g. Jellema et al. 2017, which revealed that VAT has a positive marginal impact on inequality in Indonesia.

Column B of the first part of Table 8 reports the actual redistributive effect of the 2020 VAT scheme. Similar to the old VAT scheme, the 2020 scheme also produces a negligible increase in the Gini coefficient. This finding is strengthened using the Lorenz curves shown in Figure 3 in the appendix. In this figure, the Lorenz curves of the various schemes lie on top of each other. Though the increase in inequality is negligible it is just a bit higher relative to the increase (0.002) witnessed in the pre-2020 scheme at the national level. More so, the urban and rural level effects remain very similar and roughly very marginal. Overall, the observed increase could be attributable to the increase in the policy VAT rate from 5 per cent to 7.5 per cent by the federal government in the early 2020 period. Further, as can be seen in column B, the 2020 VAT scheme increased poverty by 0.6 per cent - roughly 1 per cent at the national level, 0.5 per cent at the urban level and 0.6 per cent at the rural level. These proportions are slightly higher than the values reported ( 0.4 per cent, 0.3 per cent and 0.4 per cent respectively) as the effects of pre-2020 VAT on poverty. This change is of no surprise following the 50 per cent increase in VAT as mentioned above. Intuitively, the currently increased policy VAT rate will likely push some more Nigerians below the poverty line. Notably, the results for the poverty gap and severity produce an identical pattern, as seen in column A and B of the first part of Table 8.

The second part of Table 8 also presents the redistributive effect of VAT, but after accounting for the informal sector. As mentioned previously, this study has accounted for informality in the calculation of VAT by using macroeconomic data (comprising of administrative and 
national account data). In line with previous related studies (e.g. Schaffer and Turley 2001; Inchauste and Rubil 2017), the current study has specifically calculated the effective VAT rate by using the total value of VAT revenue collections (from the Federal Inland Revenue Service) ${ }^{25}$ divided by the total value of all goods and services subject to VAT (data compiled by the Nigeria National Bureau of Statistics). ${ }^{26}$ The calculated effective rate was then applied to the household purchases subject to VAT (Inchauste and Rubil 2017). As seen in column A of the second part of Table 8, the pre-2020 scheme increased the Gini coefficient by a lesser point (0.001) compared to the point recorded (0.002) without correcting for the informal sector at the national level. Notably, the regional level results, as seen in Table 8, remain very negligible. But overall the fact that the pre-2020 scheme Gini with informal correction was increased by a lesser point compared to the point recorded without informal sector correction means that accounting for the informal sector in the analyses leads to a lesser change in income inequality. Similarly, we observe a lesser change in poverty headcount at national ( 0.25 per cent), urban ( 0.15 per cent), and rural $(0.30$ per cent) levels compared to the proportion seen at the national $(0.4$ per cent), urban ( 0.3 per cent) and rural $(0.4$ per cent) levels when we fail to account for the informal sector. Further, the redistributive effect of the current VAT scheme corrected for the presence of the informal sector reveals a similar direction. In terms of comparison across schemes, the estimated effects of the current VAT scheme on inequality and poverty as seen in column B of Table 8 are slightly higher than the estimated values of the previous VAT scheme both without and with the informal sector correction. This of course is expected since the effective rate in the current VAT scheme is also slightly higher than that of the previous scheme.

\footnotetext{
25 The OECD, African Union Commission (AUC) and African Tax Administration Forum (ATAF) have reported detailed FIRS tax revenue composition data for the year 2018 in Nigeria (OECD/AUC/ATAF 2020).

26 The Statistical Bulletin of the Central Bank of Nigeria reported detailed 2018 goods and services data compiled by the NBS for Nigeria (Central Bank of Nigeria 2018).
} 


\section{Discussion and conclusion}

This study attempts to address two related specific questions. First, what is the progressivity of income tax and VAT reforms in Nigeria? Second, what is the distributional effect of income tax and VAT reforms in Nigeria? In line with these specific questions, the current study yields several crucial findings. First, income tax was found to be progressive in the pre-2011 reform scheme but became regressive in the post-2011 reform scheme. It was also found that the newly introduced lump sum relief allowance concentrates more in the high-income than in the low-income taxpayers - confirming the regressivity of the post-2011 PIT scheme. However, the study uncovered that the regulation of the relief allowance in the post-2011 PIT scheme decreases the PIT regressivity. Of more interest is that if the variable part of the relief allowance in the post-2011 PIT scheme is reserved only for low-income taxpayers below a predefined income threshold, entirely excluding high-income taxpayers, the current PIT scheme becomes progressive. The above regressivity of the post-2011 PIT is also partly attributable to a tax table that barely differentiates the middle (low) income from high-income earners, since virtually most middle-income earners tend to reach a high marginal tax level. The tax brackets in the 2011 PIT scheme have been increased and this puts low-income earners in high tax bases and rates. However, in reality low-income earners in Nigeria are barely able to raise their wages, plus a minimum wage is hardly ever implemented to cover inflated prices. The regressivity of the post-2011 PIT could also be partly ascribed to the increase in the minimum tax rate (low-income tax rate) from 0.5 per cent in the pre-2011 scheme to 1 per cent in the post-2011 scheme. Further, the post-2011 PIT regressivity result is similar to what was found in Hirvonen et al. 2016 and Mascagni et al. 2016, that a tax system initially designed to be progressive can still turn to be regressive. The VAT was regressive both in the pre-2020 scheme and in the current VAT reform scheme. The results for VAT are not far from what one would expect, since indirect taxes (e.g. VAT at fixed rates) are usually regressive (the poor paying more through increased purchases of vatable goods) probably because of its flat rate (everyone paying the same amount regardless of income size) (Younger and Khachatryan 2017; Alam, Inchauste and Serajuddin 2017; Arunatilake et al. 2017). Although VAT in Nigeria has a number of exemptions, they do not affect the progressivity of the tax instrument, and the higher income taxpayers tend to benefit the most from these exemptions (exemptions that are not pro-poor) in value terms.

The answer to the second question in the pre-2011 PIT scheme is that limited redistribution occurred. The study disclosed pre-2011 PIT to have marginally reduced inequality, but on the converse increased poverty. The post-2011 PIT scheme reduced inequality and increased poverty but by a smaller proportion. The negligible redistributive results, as mentioned above, are attributable to the concentration of the lump sum relief allowance at the top of the distribution - consisting mainly of high-income taxpayers (see Figure 1). However, a larger redistributive effect is observed if high-income taxpayers above or equal to a predefined income threshold are entirely excluded from sharing in the variable part of the relief allowance. The limited redistributive role of the current PIT scheme could also be partly attributed to the exclusion of the large informal sector (nowadays some of the high-income people hide their businesses in the informal sector in order to dodge taxes) from the nation's tax net, resulting in low tax collections (similarly as found in Jellema et al. (2017) for Indonesia). Hence, the need for the government to not only regulate the relief allowance but also capture the informal sector incomes, and at the same time maintain the basic equity and fairness principles of taxation. The finding of little income redistributive effect is consistent with the work of Hirvonen et al. (2016), which revealed that taxation had a negligible effect on Ethiopia's Gini index. More so, the contradictory results of reduction in inequality and increase in poverty resulting from income tax is in accord with Lustig and Higgins (2012) and Inchauste and Lustig (2017), suggesting that an inequality-reducing tax system could also be poverty increasing, and that this cannot be exposed without a detailed empirical analysis. 
The VAT was revealed to marginally increase both inequality and poverty in the pre-2020 scheme. More so, the 2020 VAT scheme slightly increased inequality, but significantly increased poverty - a result similar to what was reported in Hill et al. (2017) and Arunatilake et al. (2017) for Ethiopia and Sri Lanka respectively.

It is crucial to systematically weigh some caveats and corresponding assumptions relied upon, together with the consequences of relaxing these assumptions on the analyses of the current study.

First, the study had no access to the real PIT variable. Hence, following existing studies, it obtained a proxy variable for PIT by applying the tax rules on incomes of individual households. This was done, assuming that people pay their complete taxes as stipulated by the law. Specifically, it is assumed that the calculated PIT is a good proxy of the real PIT. The study has relied on this assumption, since it has no access to administrative data containing the real tax amount that people actually pay. But what would have happened to the results if the paper was able to access and use the real PIT variable? If this had been possible, the clear consequence would have been that the incidence and redistribution analyses would have yielded lesser estimates. This is simply because in reality people have the tendency to dodge or understate their taxes.

Second, household surveys are widely known to understate income, since people tend to underreport their own income. This means that income is measured with some significant error. Hence, in this study it is assumed that correcting for income underreporting using 'better' collected consumption data provides a better living standard measure for correct analysis. Although the study has accounted for the quality of the income variable using the consumption expenditure from the survey data, it still acknowledges the limitations (which mainly entail that surveys exclude top income earners) described in subsection 4.2. However, what would the results have looked like if the study had utilised the income variable without correcting for underreporting? If the study had directly employed the raw (survey) income variable, the consequence is that the incidence and redistribution analyses would have been underestimated. But since this study has used the most recent large nationally representative living standard survey, it is believed that the adjusted income data can still be used as a reasonable representation of reality to undertake analyses of the incidence and redistributive effect of taxes.

Third, since oil related taxes (CIT) contribute a large share to Nigeria's total tax revenue, it is important to calculate their incidence and redistributive effects. However, data relating to these taxes is not in the Nigeria survey. Since there is no properly recorded oil related data/CIT in the survey, the study cannot directly allocate these type of taxes to individual households to enable meaningful analyses. Hence, the main analyses in this work only focus on taxes (PIT and VAT) relevant to households, and not on CIT, which involves several uncertain assumptions, making it very difficult to determine the distribution of its final economic incidence (Ataguba 2012; Inchauste and Lustig 2017). If the study had accounted for CIT, total household taxes would have been overstated, since these taxes are not directly relevant to micro households.

Fourth, this study has assumed a very simple micro-simulation model, unable to study the entire fiscal system. It has only considered two specific taxation policies, rather than the entire fiscal system. The study has relied on this assumption mainly due to data limitations. On the taxation side, the simulation model is not able to analyse more than the PIT and VAT policy instruments, since the survey data does not contain adequate information to calculate CIT or oil related taxes. On the expenditure side, the study does not have enough information on transfers and subsidies that the government grants to poor households. However, if the assumption here was relaxed, and there was access to adequate information on taxation and expenditure policies, then the simulation model would have yielded a more 
detailed analysis on the net effect of fiscal policies on poverty and income inequality. More so, the simple model does not account for behavioural and second round effects. Otherwise, the inequality and poverty dynamics estimated in this work would be interpreted as demonstrating purely causal effects of changing taxation policies.

Fifth, the study assumes that informal sector activities evade taxes. Hence, the tax laws have only been applied on formal sector earnings. Although the living standard survey utilised in this paper differentiates between formal and informal incomes, the study is somewhat hampered from applying the tax rule on informal incomes. It has accounted for informality by applying the formal PIT laws on formal earnings and the effective VAT rates on household taxable consumption expenditures respectively. Hence the conclusions reached here are mainly focused on formal taxes. This is because informal participants tend to dodge taxes. Notably, the current study has only described the size of household participation in economic activities in both formal and informal sectors, with their corresponding annual average incomes. This description (see Table 2 above) exposed a large under and untaxed informal sector, relative to the small, taxed formal sector. Hence, the need for government effort to draw informal sector workers into the national tax net. But what change would have occurred to the main results had the study entirely ignored the existence of the informal sector? If the study had failed to account for informality, and directly applied the tax rules on both formal and informal earnings, then the change in the results would be an overestimate of the true equity and redistributive effect of PIT and VAT.

Regardless of the limitations mentioned above, the results from this study are still consistent with the outcomes of related previous studies in the taxation literature, and this supports the validity of its analysis. First, in line with previous studies, the equity analysis suggests that income taxation initially designed to be progressive may still turn out to be regressive. Meticulous tax reform, with regulated relief allowance (entirely excluding high-income taxpayers from sharing in the variable part) and well-targeted higher rates for the wealthy class, could be helpful in enhancing the equity and redistributive potential of the income tax policy. It is also suggested that differentiated VAT rates, i.e. a higher rate on luxury items and a lesser rate on consumable items, may help to achieve better fairness and redistribution of the VAT policy instrument in Nigeria. 


\section{References}

Adekanola, O. (1997) 'Efficient Tax Collection and Effective Tax Administration in Nigeria', paper presented at a seminar organised by the University of Lagos Consultancy Services, Otta, 15 May

Alam, S.A., Inchauste, G., and Serajuddin, U. (2017) The Distributional Impact of Fiscal Policy in Jordan, CEQ Working Paper 44, Commitment to Equality Institute, Tulane University and the World Bank

Anyaduba, J.O. and Otulugbu, P.O. (2019) 'Taxation and Income Inequality in Nigeria', Accounting and Finance Research 8.3: 118-135

Arunatilake, N., Inchauste, G. and Lustig, N. (2017) The Incidence of Taxes and Spending in Sri Lanka, CEQ Working Paper 63, Commitment to Equality Institute, Tulane University and the World Bank

Ataguba, J.E. (2012) 'Distributional Impact of Healthcare Finance in South Africa', PhD thesis, University of Cape Town

Atkinson, A.B., Piketty, T. and Saez, E. (2011) 'Top Incomes in the Long Run of History', Journal of Economic Literature 49.1: 3-71

Avram, S. (2017) 'Who Benefits from the "Hidden Welfare State"? The Distributional Effects of Personal Income Tax Expenditure in Six Countries', Journal of European Social Policy 28.3: 271-293

Bachas, P., Gadenne, L. and Jensen, A. (2020) Informality, Consumption Taxes, and Redistribution, National Bureau of Economic Research (NBER) Working Paper 27429

Bird, R.M., and Zolt, E.M. (2005) 'The Limited Role of the Personal Income Tax in Developing Countries', Journal of Asian Economics 16.6: 928-46

Blasco, J., Guillaud, E. and Zemmour, M. (2020) The Impact of Consumption Taxes on Income Inequality: An International Comparison, LIS Working Paper Series 785

Cancho, C. and Bondarenko, E. (2017) The Distributional Impact of Fiscal Policy in Georgia, CEQ Working Paper 42, Commitment to Equality Institute, Tulane University and the World Bank

Cano, L., (2017) 'Personal Income Tax and Income Inequality in Ecuador Between 2007 and 2011', CEPAL Review 123: 57-75

Causa, O. and Hermansen, M. (2017). Income Redistribution through Taxes and Transfers across OECD Countries, Economics Department Working Paper 1453

Central Bank of Nigeria (CBN) (2018) The CBN Statistical Bulletin, 2018

Cubero, R. and Hollar, I.V. (2010) Equity and Fiscal Policy: The Income Distribution Effects of Taxation and Social Spending in Central America, IMF Working Paper WP/10/112

Deaton, A. and Zaidi, S. (2002) Guidelines for Constructing Consumption Aggregates, LSMS Working Paper 135, Washington, DC: World Bank 
Decoster, A. and Verbina, I. (2003) Who Pays Indirect Taxes in Russia? UNU/WIDER Discussion Paper 2003/58

Development Finance International and Oxfam (2020) Fighting Inequality in the Time of Covid-19: The Commitment to Reducing Inequality Index 2020, Oxford: Development Finance International and Oxfam International

Du, L. and Zhang, Z.X. (2018) 'Measuring the Redistributive Effects of China's Personal Income Tax', Asia \& the Pacific Policy Studies 5.2: 220-234

Duclos, J.Y., Jalbert, V. and Araar, A. (2003) 'Classical Horizontal Inequity and Reranking: An Integrated Approach', in Y. Amiel and J.A. Bishop (eds.) Fiscal Policy, Inequality and Welfare (Research on Economic Inequality Vol. 10), Bingley: Emerald Group

Egbon, O. and Mgbame, C.O. (2015) 'What Is Progressive about Nigerian Personal Income Tax?', JORIND 13.1: 228-239

Engel, E.M.R.A., Galetovic, A. and Raddatz, C.E. (1999) 'Taxes and Income Distribution in Chile: Some Unpleasant Redistributive Arithmetic', Journal of Development Economics 59: 155-192

Farfan-Portet, M-I., Hindriks, J. and Lorant, V. (2008) 'Progressivity of Childcare Tax Policies in Belgium', Louvain Economic Review 74.2: 143-165

Faridy, N. and Sarker, T. (2011) 'Incidence of Value Added Tax in the Developing Countries: A Case in Bangladesh', International Journal of Trade, Economics and Finance 2.5: 437

Federal Republic of Nigeria (2011) Official Gazette of Federal Republic of Nigeria, PIT Act, 2011, https://pwcnigeria.typepad.com/files/pit-amendment---gazetted-14-june-2011.pdf

Federal Republic of Nigeria (1993) Personal Income Tax Act No. 104, https://www.icnl.org/research/library/nigeria_7_nigeriapita1993/

Foster, J., Greer, J. and Thorbecke, E. (1984) 'A Class of Decomposable Poverty Measures', Econometrica 52.3: 761-766

Gemmell, N. and Morrissey, O. (2005) 'Distribution and Poverty Impacts of Tax Structure Reform in Developing Countries: How Little We Know', Development Policy Review 23.2: $131-44$

Hill, R., Inchauste, G., Lustig, N., Tsehaye, E. and Woldehanna, T. (2017) A Fiscal Incidence Analysis for Ethiopia, CEQ Working Paper 41, Commitment to Equality Institute, Tulane University and the World Bank

Hirvonen, K., Mascagni, G. and Roelen, K. (2016) Linking Taxation and Social Protection: Evidence on Redistribution and Poverty Reduction in Ethiopia, ICTD Working Paper 61, Brighton: Institute of Development Studies

Ichoku, H.E. and Anuku, W. (2019) 'The Redistributive Effect of Taxation in Nigeria', Journal of Academic Research in Economics 11.3: 580-603 
Inchauste, G. and Lustig, N. (2017) The Distributional Impact of Taxes and Transfers:

Evidence from Eight Low- and Middle-Income Countries. Directions in Development, Washington, DC: World Bank

Inchauste, G. and Rubil, I. (2017) The Distributional Impact of Taxes and Social Spending in Croatia, Poverty and Equity Global Practice Working Paper 120

Inchauste, G., Lustig, N., Maboshe, M., Purfield, C. and Woolard, I. (2015) The Distributional Impact of Fiscal Policy in South Africa, World Bank Policy Research Working Paper 7194

Jenkins, G.P., Jenkins, H. and Kuo, C-Y. (2006) Is the Value Added Tax Naturally Progressive? Queen's Economics Department Working Paper 1059

Jellema, J., Wai-Poi, M. and Afkar, R. (2017) The Distributional Impact of Fiscal Policy in Indonesia, CEQ Working Paper 40, Commitment to Equality Institute, Tulane University and the World Bank

Jellema, J., Lustig, N., Haas, A. and Wolf, S. (2016) The Impact of Taxes, Transfers, and Subsidies on Inequality and Poverty in Uganda, CEQ Working Paper 53, Commitment to Equality Institute, Tulane University and the World Bank

Jibao, S., Prichard, W. and van den Boogaard, V. (2017) Informal Taxation in Post-Conflict Sierra Leone: Taxpayers' Experiences and Perceptions, ICTD Working Paper 66, Brighton: Institute of Development Studies

Kakwani, N.C. (1977) 'Measurement of Tax Progressivity: An International Comparison', Economic Journal 87: $71-80$

Lokshin, M. and Sajaia, Z. (2006) 'EGEN_INEQUAL: Stata Module Providing Extensions to Generate Inequality and Poverty Measures', Statistical Software Components, Boston College Department of Economics

Lustig, N. and Higgins, S. (2012) Commitment to Equity Assessment (CEQ): Estimating the Incidence of Social Spending, Subsidies and Taxes Handbook, Tulane Economics Working Paper 1219, Tulane University

Lustig, N., Pessino, C. and Scott, J. (2013) The Impact of Taxes and Social Spending on Inequality and Poverty in Argentina, Bolivia, Brazil, Mexico, Peru and Uruguay: An Overview, CEQ Working Paper 13, Center for Inter-American Policy and Research and Department of Economics, Tulane University and Inter-American Dialogue

Lyon, A.B. and Schwab, R. (1995) 'Consumption Taxes in a Life-cycle Framework: Are Sin Taxes Regressive?', The Review of Economics and Statistics 77: 389-406

Mascagni, G., Monkam, N. and Nell, C. (2016) Unlocking the Potential of Administrative Data in Africa: Tax Compliance and Progressivity in Rwanda, ICTD Working Paper 56, Brighton: Institute of Development Studies

Martinez-Vazquez, J., Moreno-Dodson, B. and Vulovic, V. (2012) The Impact of Tax and Expenditure Policies on Income Distribution: Evidence from a Large Panel of Countries, Working Paper 12-25, International Center for Public Policy

Musgrave, R.A. and Thin, T. (1948) 'Income Tax Progression, 1929-48', The Journal of Political Economy 56: 498-514 
NBS (2020) 2019 Poverty and Inequality in Nigeria: Executive Summary

NBS (2018) Snapshot of Inequality in Nigeria - 2004, 2015, 2016, Abuja: NBS

NBS (2014) Nigerian Gross Domestic Product Report, Quarter Four, nigerianstat.gov.ng/download/272

NBS (2012) Nigeria Poverty Profile 2010, https://reliefweb.int/report/nigeria/nigeria-povertyprofile-2010-report

NLSS (2018/2019) Nigeria Living Standard Survey. http://microdata.worldbank.org/index.php/catalog/3827

Nyamongo, M.E. and Schoeman, N.J. (2007) 'Tax Reform and the Progressivity of Personal Income Tax in South Africa', South African Journal of Economics 75.3: 478-495

Obaretin, O., Akhor, S.O. and Oseghale, O.E. (2017) 'Taxation an Effective Tool for Income Re-Distribution in Nigeria', Mediterranean Journal of Social Sciences 8.4: 187-196

Oboh, T. and Eromonsele, P.E. (2018) 'Taxation and Income Inequality in Nigeria', NGJournal of Social Development 7.1: 63-72

O'Donnell, O., Van Doorslaer, E., Wagstaff, A. and Lindelow, M. (2008) Analysing Health Equity Using Household Survey Data: A Guide to Techniques and Their Implementation, Washington, DC: World Bank Publications

OECD/AUC/ATAF (2020) Revenue Statistics in Africa 2020: 1990-2018, Paris: OECD Publishing

Osakwe, J.O. (1999) 'Recent Reforms in Personal Income Taxation in Nigeria', CBN Economic and Financial Review 37.3: 18-43

Phillips, D., Warwick, R., Goldman, M., Goraus, K., Inchauste, G., Harris, T. and Jellema, J. (2018) Redistribution Via VAT and Cash Transfers: An Assessment in Four Low and Middle Income Countries, CEQ Working Paper 78, Commitment to Equality Institute, Tulane University and the World Bank

Popescu, M.E., Militaru, E., Stanila, L., Vasilescu, M.D. and Cristescu, A. (2019) 'Flat-Rate Versus Progressive Taxation? An Impact Evaluation Study for the Case of Romania', Sustainability 11.22, 6405

PricewaterhouseCoopers (PwC) (2012) 'The Personal Income Tax (Amendment) Act 2011', https://pwcnigeria.typepad.com/tax_matters_nigeria/2012/01/the-personal-income-taxamendment-act-2011.html

Rafaqat, S. (2003) Social Incidence of the General Sales Tax in Pakistan, IMF Working Paper 03/216, Washington, DC: International Monetary Fund

Rajemison, H., Haggblade, S. and Younger, S. (2003) Indirect Tax Incidence in Madagascar: Updated Estimates Using the Input-Output Table, Ithaca, New York: Cornell Food and Nutrition Policy Program 
Sajaia, Z. (2007) 'FASTGINI: Stata Module to Calculate Gini Coefficient with Jack-knife Standard Errors', Statistical Software Components, Boston College Department of Economics

Sarah, S.N. and Kasirye, I. (2015) Progressivity or Regressivity in Uganda's Tax System: Implications for the Fy2014/15 Tax Proposals, Economic Policy Research Centre (EPRC) Research Series 123

Sarker, T.K. (2006) 'Who Bears the Burden of Taxes in Developing Countries? A Case of Income Taxation in Bangladesh', Pakistan Economic and Social Review 44.2: 181-207

Schaffer, M.E. and Turley, G. (2001) Effective Versus Statutory Taxation: Measuring Effective Tax Administration in Transition Economies, Working Paper 62, European Bank for Reconstruction and Development

Schmutz, F. and Schaltegger, C.A. (2018) Progressive VAT? The redistributive effects of VAT Rate Differentiation, https://zenodo.org/record/1422789\#.YXCvyxwo_IU

Sivashankar, P., Rathnayake, R.M.P.S., Jayasinghe, M. and Smith, C. (2017). Incidence of Value Added Taxation on Inequality: Evidence from Sri Lanka, Working Paper 2017-04, Griffith University

Thomas, A. (2020). Reassessing the Regressivity of VAT, OECD Taxation Working Paper 49, OECD

Toé, N., Diallo, A., Barhoumi, K., Towfighian, S.N. and Maino, R. (2017) Fiscal Incidence and Inequality, IMF Country Report 18/2, IMF

UNU-WIDER (2021) World Income Inequality Database (WIID), User Guide and Data Sources, https://www.wider.unu.edu/sites/default/files/WIID/WIID-User-Guide31MAY2021.pdf

van den Boogaard, V., Prichard, W., and Jibao, S. (2018)' Informal Taxation in Sierra Leone: Magnitudes, Perceptions and Implications', African Affairs 118/471: 259-284

Verbist, G. and Figari, F. (2013) The Redistributive Effect and Progressivity of Taxes Revisited: An International Comparison across the European Union, Gini Discussion Paper 88

Warren, N. (2008) A Review of Studies on the Distributional Impact of Consumption Taxes in OECD Countries, OECD Social, Employment and Migration Working Papers 64

World Bank (2019) Nigeria Digital Economy Diagnostic Report, Washington, DC: World Bank, https://openknowledge.worldbank.org/handle/10986/32743

World Bank (2016) Poverty Reduction in Nigeria in the Last Decade, Washington, DC: World Bank

World Bank (2013) Nigeria: Where has All the Growth Gone? Washington, DC: World Bank

World Bank Group (2020) Rising to the Challenge: Nigeria's COVID Response, Nigeria Development Update 2020

World Bank Group (2019) Jumpstarting Inclusive Growth: Unlocking the Productive Potential of Nigeria's People and Resource Endowments, Nigeria's Economic Update, Fall 2019 
World Development Indicators (WDI) (2020)

https://databank.worldbank.org/reports.aspx?source=2\&series=NY.GDP.MKTP.KD.ZG \& country $=\mathrm{NGA}$

Younger, S.D., and Khachatryan, A. (2017) Fiscal Incidence in Armenia, CEQ Working Paper 43, Commitment to Equality Institute, Tulane University and the World Bank 


\section{Appendix}

\section{Tables and figures}

Table 9 Pre-2011 income tax structure in Nigeria, 1993 laws

\begin{tabular}{|l|l|l|l|}
\hline s/n & Steps & Taxable income & Tax rate \\
\hline 1 & First & 20,000 & $5 \%$ \\
\hline 2 & Second & 20,000 & $10 \%$ \\
\hline 3 & Third & 40,000 & $15 \%$ \\
\hline 4 & Fourth & 40,000 & $20 \%$ \\
\hline 5 & Above & 120,000 & $25 \%$ \\
\hline
\end{tabular}

Source: Federal Republic of Nigeria, PIT Act, No. 104, 1993.

Note: ${ }^{1}$ Thresholds of annual income.

${ }^{2}$ Individuals with no taxable income are charged $0.5 \%$ of their total income.

Table 10 Post-2011 income tax structure in Nigeria, 2011 to date

\begin{tabular}{|l|l|l|l|}
\hline$s / n$ & Steps & Taxable income & Tax rate \\
\hline 1 & First & 300,000 & $7 \%$ \\
\hline 2 & Second & 300,000 & $11 \%$ \\
\hline 3 & Third & 500,000 & $15 \%$ \\
\hline 4 & Fourth & 500,000 & $19 \%$ \\
\hline 5 & Fifth & $1,600,000$ & $21 \%$ \\
\hline 6 & Above & $3,200,000$ & $24 \%$ \\
\hline
\end{tabular}

Source: Official Gazette of Federal Republic of Nigeria, PIT (Amendment) Act, 2011

Note: ${ }^{1}$ Thresholds of annual income.

${ }^{2}$ Individuals with no taxable income are charged $1 \%$ of their total income.

Table 11 Description of the simulation scenarios for the redistributive effect of PIT

\begin{tabular}{|l|l|l|l|}
\hline & $\mathbf{0}$ & N1 & N2 \\
\hline Income components & Base & Pre-2011 PIT & Post-2011 PIT \\
\hline Labour income & X & N1 & N2 \\
\hline Crop income & X & X & X \\
\hline Livestock income & X & X & X \\
\hline Fishing income & X & X & X \\
\hline Self-employment income & X & N1 & N2 \\
\hline Transfers income & X & $X$ & X \\
\hline Other income & $X$ & $X$ & $X$ \\
\hline
\end{tabular}

Source: Author's description.

Note: $\mathrm{X}=$ values estimated from the survey. $\mathrm{N} 1=$ net of PIT (pre-2011 scheme).

$\mathrm{N} 2$ = net of PIT (post-2011 scheme).

Table 12 Description of the simulation scenarios for the redistributive effect of VAT

\begin{tabular}{|l|l|l|l|}
\hline & $\mathbf{0}$ & N1 & N2 \\
\hline Consumption components & Base & Pre-2020 VAT & Post-2020 VAT \\
\hline Vatable items & X & N1 & N2 \\
\hline Non-vatable items & X & X & X \\
\hline Other non-food items & X & $X$ & $X$ \\
\hline Total food items & X & X & X \\
\hline
\end{tabular}

Source: Author's description.

Note: $\mathrm{X}=$ values estimated from the survey. $\mathrm{N} 1=$ net of VAT (pre-2020 scheme)

$\mathrm{N} 2$ = net of VAT (post-2020 scheme). 
Table 13 Confidence intervals of average incomes of Nigeria households

\begin{tabular}{|c|c|c|rr|}
\hline Variable & Mean & Std. dev. & \multicolumn{2}{|c|}{ Conf. interval } \\
\hline Wage employment & & & & \\
\hline Nigeria & 802127.4 & 2307513.6 & $746226.6 \quad 858028.3$ \\
\hline Urban & 944851 & 1890452.1 & 875477.3 & 1014225 \\
\hline Rural & 691790.1 & 1890452.1 & $608582.7 \quad 774997.6$ \\
\hline Farming activity & & & & \\
\hline Nigeria & 73165.5 & 286883.54 & 69384.77 & 76946.22 \\
\hline Urban & 39727.86 & 382579 & 30644.44 & 48811.29 \\
\hline Rural & 88059.93 & 230332.58 & 84410.41 & 91709.44 \\
\hline Self-employment & & & & \\
\hline Nigeria & 912862.7 & 4172222.1 & 852480.5 & 973244.9 \\
\hline Urban & 1263510 & 5832248.5 & 1122895 & 1404124 \\
\hline Rural & 715272.5 & 2818288.1 & 664269.9 & 766275.1 \\
\hline
\end{tabular}


Table 14 Confidence intervals of estimated effects of PIT under each scenario

\begin{tabular}{|c|c|c|c|}
\hline \multicolumn{4}{|c|}{ Estimates without informal sector correction } \\
\hline Variable & Mean & Std. dev. & Conf. interval \\
\hline \multicolumn{4}{|c|}{ National estimates } \\
\hline \multicolumn{4}{|l|}{ Inequality indicator } \\
\hline 0Gini & 0.3895 & 0.0029 & $\begin{array}{ll}0.3836 & 0.3953\end{array}$ \\
\hline 1Gini & 0.3737 & 0.0030 & $\begin{array}{ll}0.3678 & 0.3797\end{array}$ \\
\hline 2Gini & 0.3869 & 0.0028 & 0.38120 .3925 \\
\hline \multicolumn{4}{|l|}{ Poverty headcount } \\
\hline Opov0 & 0.4183 & 0.0000 & $0.4183 \quad 0.4183$ \\
\hline 1 pov0 & 0.4622 & 0.0000 & $0.4622 \quad 0.4622$ \\
\hline 2 pov0 & 0.4224 & 0.0000 & $0.4224 \quad 0.4224$ \\
\hline \multicolumn{4}{|l|}{ Poverty gap } \\
\hline 0pov1 & 0.1749 & 0.0000 & $0.1749 \quad 0.1749$ \\
\hline 1 pov1 & 0.1906 & 0.0000 & $0.1906 \quad 0.1906$ \\
\hline 2pov1 & 0.1768 & 0.0000 & $\begin{array}{ll}0.1768 & 0.1768\end{array}$ \\
\hline \multicolumn{4}{|l|}{ Poverty severity } \\
\hline 0pov2 & 0.1079 & 0.0000 & $\begin{array}{ll}0.1079 & 0.1079\end{array}$ \\
\hline 1pov2 & 0.1154 & 0.0000 & $0.1154 \quad 0.1154$ \\
\hline 2pov2 & 0.1089 & 0.0000 & $0.1089 \quad 0.1089$ \\
\hline \multicolumn{4}{|c|}{ Urban estimates } \\
\hline \multicolumn{4}{|l|}{ Inequality indicator } \\
\hline 0Gini & 0.3614 & 0.0064 & $\begin{array}{ll}0.3489 & 0.3739\end{array}$ \\
\hline 1Gini & 0.3478 & 0.0066 & $\begin{array}{ll}0.3348 & 0.3608\end{array}$ \\
\hline 2Gini & 0.3571 & 0.0062 & $0.3450 \quad 0.3693$ \\
\hline \multicolumn{4}{|l|}{ Poverty headcount } \\
\hline Opov0 & 0.2308 & 0.0000 & $\begin{array}{ll}0.2308 & 0.2308\end{array}$ \\
\hline 1 pov0 & 0.2670 & 0.0000 & $\begin{array}{ll}0.2670 & 0.2670\end{array}$ \\
\hline $2 p o v 0$ & 0.2340 & 0.0000 & $0.2340 \quad 0.2340$ \\
\hline \multicolumn{4}{|l|}{ Poverty gap } \\
\hline 0pov1 & 0.1021 & 0.0000 & $\begin{array}{ll}0.1021 & 0.1021\end{array}$ \\
\hline 1 pov1 & 0.1117 & 0.0000 & $\begin{array}{ll}0.1117 & 0.1117\end{array}$ \\
\hline $2 p o v 1$ & 0.1031 & 0.0000 & $\begin{array}{ll}0.1031 & 0.1031\end{array}$ \\
\hline \multicolumn{4}{|l|}{ Poverty severity } \\
\hline 0pov2 & 0.0745 & 0.0000 & $\begin{array}{ll}0.0745 & 0.0745\end{array}$ \\
\hline 1pov2 & 0.0781 & 0.0000 & $\begin{array}{ll}0.0781 & 0.0781\end{array}$ \\
\hline 2pov2 & 0.0749 & 0.0000 & $\begin{array}{ll}0.0749 & 0.0749\end{array}$ \\
\hline
\end{tabular}




\begin{tabular}{|c|c|c|c|}
\hline Rural estimates & & & \\
\hline \multicolumn{4}{|l|}{ Inequality indicator } \\
\hline 0Gini & 0.3763 & 0.0026 & $\begin{array}{ll}0.3712 & 0.3813\end{array}$ \\
\hline 1Gini & 0.3606 & 0.0025 & $\begin{array}{ll}0.3557 & 0.3655\end{array}$ \\
\hline 2Gini & 0.3747 & 0.0025 & $\begin{array}{ll}0.3698 & 0.3796\end{array}$ \\
\hline \multicolumn{4}{|l|}{ Poverty headcount } \\
\hline Opov0 & 0.5018 & 0.0000 & $\begin{array}{ll}0.5018 & 0.5018\end{array}$ \\
\hline 1pov0 & 0.5491 & 0.0000 & $\begin{array}{ll}0.5491 & 0.5491\end{array}$ \\
\hline $2 p o v 0$ & 0.5063 & 0.0000 & $\begin{array}{ll}0.5063 & 0.5062\end{array}$ \\
\hline \multicolumn{4}{|l|}{ Poverty gap } \\
\hline 0pov1 & 0.2074 & 0.0000 & $\begin{array}{ll}0.2074 & 0.2074\end{array}$ \\
\hline 1pov1 & 0.2258 & 0.0000 & $\begin{array}{ll}0.2258 & 0.2258\end{array}$ \\
\hline 2pov1 & 0.2097 & 0.0000 & $\begin{array}{ll}0.2097 & 0.2097\end{array}$ \\
\hline \multicolumn{4}{|l|}{ Poverty severity } \\
\hline 0pov2 & 0.1228 & 0.0000 & $\begin{array}{ll}0.1228 & 0.1228\end{array}$ \\
\hline 1pov2 & 0.1321 & 0.0000 & $\begin{array}{ll}0.1321 & 0.1321\end{array}$ \\
\hline 2pov2 & 0.1241 & 0.0000 & $\begin{array}{ll}0.1241 & 0.1241\end{array}$ \\
\hline \multicolumn{4}{|c|}{ Estimates with informal sector correction } \\
\hline Variable & Mean & Std. dev. & Conf. interval \\
\hline \multicolumn{4}{|l|}{ National estimates } \\
\hline \multicolumn{4}{|l|}{ Inequality indicator } \\
\hline 0Gini & 0.3895 & 0.0029 & $0.3836 \quad 0.3953$ \\
\hline 1Gini & 0.3888 & 0.0029 & $0.3829 \quad 0.3946$ \\
\hline 2Gini & 0.3894 & 0.0029 & $0.3836 \quad 0.3953$ \\
\hline \multicolumn{4}{|l|}{ Poverty headcount } \\
\hline 0pov0 & 0.4183 & 0.0000 & $0.4183 \quad 0.4183$ \\
\hline 1 pov0 & 0.4222 & 0.0000 & $0.4222 \quad 0.4222$ \\
\hline 2pov0 & 0.4189 & 0.0000 & $0.4189 \quad 0.4189$ \\
\hline \multicolumn{4}{|l|}{ Poverty gap } \\
\hline 0pov1 & 0.1749 & 0.0000 & $0.1749 \quad 0.1749$ \\
\hline 1pov1 & 0.1765 & 0.0000 & $0.1765 \quad 0.1765$ \\
\hline 2pov1 & 0.1751 & 0.0000 & $\begin{array}{ll}0.1751 & 0.1751\end{array}$ \\
\hline \multicolumn{4}{|l|}{ Poverty severity } \\
\hline 0pov2 & 0.1079 & 0.0000 & $\begin{array}{ll}0.1079 & 0.1079\end{array}$ \\
\hline 1pov2 & 0.1087 & 0.0000 & $0.1087 \quad 0.1087$ \\
\hline 2pov2 & 0.1080 & 0.0000 & $0.1080 \quad 0.1080$ \\
\hline Urban estimates & & & \\
\hline
\end{tabular}




\begin{tabular}{|c|c|c|c|c|}
\hline \multicolumn{5}{|l|}{ Inequality indicator } \\
\hline 0Gini & 0.3614 & 0.0064 & 0.3489 & 0.3739 \\
\hline 1Gini & 0.3610 & 0.0064 & 0.3484 & 0.3735 \\
\hline 2Gini & 0.3613 & 0.0064 & 0.3488 & 0.3738 \\
\hline \multicolumn{5}{|l|}{ Poverty headcount } \\
\hline 0pov0 & 0.2308 & 0.0000 & 0.2308 & 0.2308 \\
\hline 1 pov0 & 0.2320 & 0.0000 & 0.2330 & 0.2330 \\
\hline 2 pov0 & 0.2313 & 0.0000 & 0.2313 & 0.2313 \\
\hline \multicolumn{5}{|l|}{ Poverty gap } \\
\hline Opov1 & 0.1021 & 0.0000 & 0.1021 & 0.1021 \\
\hline 1pov1 & 0.1027 & 0.0000 & 0.1027 & 0.1027 \\
\hline 2 pov1 & 0.1022 & 0.0000 & 0.1022 & 0.1022 \\
\hline \multicolumn{5}{|l|}{ Poverty severity } \\
\hline Opov2 & 0.0745 & 0.0000 & 0.0745 & 0.0745 \\
\hline 1pov2 & 0.0747 & 0.0000 & 0.0747 & 0.0747 \\
\hline 2 pov2 & 0.0745 & 0.0000 & 0.0745 & 0.0745 \\
\hline \multicolumn{5}{|c|}{ Rural estimates } \\
\hline \multicolumn{5}{|l|}{ Inequality indicator } \\
\hline 0Gini & 0.3763 & 0.0026 & 0.3712 & 0.3813 \\
\hline 1Gini & 0.3755 & 0.0026 & 0.3704 & 0.3805 \\
\hline 2Gini & 0.3762 & 0.0026 & 0.3712 & 0.3812 \\
\hline \multicolumn{5}{|l|}{ Poverty headcount } \\
\hline Opov0 & 0.5018 & 0.0000 & 0.5018 & 0.5018 \\
\hline 1 pov0 & 0.5039 & 0.0000 & 0.5039 & 0.5039 \\
\hline 2 pov0 & 0.5024 & 0.0000 & 0.5024 & 0.5024 \\
\hline \multicolumn{5}{|l|}{ Poverty gap } \\
\hline Opov1 & 0.2074 & 0.0000 & 0.2074 & 0.2074 \\
\hline 1 pov1 & 0.2084 & 0.0000 & 0.2084 & 0.2084 \\
\hline 2 pov1 & 0.2076 & 0.0000 & 0.2076 & 0.2076 \\
\hline \multicolumn{5}{|l|}{ Poverty severity } \\
\hline Opov2 & 0.1228 & 0.0000 & 0.1228 & 0.1228 \\
\hline 1 pov2 & 0.1233 & 0.0000 & 0.1233 & 0.1233 \\
\hline 2 pov2 & 0.1229 & 0.0000 & 0.1229 & 0.1229 \\
\hline
\end{tabular}


Table 15 Confidence intervals of estimated effects of VAT under each scenario

\begin{tabular}{|c|c|c|c|}
\hline \multicolumn{4}{|c|}{ Estimates without informal sector correction } \\
\hline Variable & Mean & Std. dev. & Conf. interval \\
\hline \multicolumn{4}{|c|}{ National estimates } \\
\hline \multicolumn{4}{|c|}{ Inequality indicator } \\
\hline 0Gini & 0.3892 & 0.0028 & $0.3835 \quad 0.3949$ \\
\hline 1Gini & 0.3911 & 0.0028 & $0.3854 \quad 0.3968$ \\
\hline 2Gini & 0.3921 & 0.0028 & $0.3864 \quad 0.3977$ \\
\hline \multicolumn{4}{|c|}{ Poverty headcount } \\
\hline 0pov0 & 0.3881 & 0.0000 & $0.3881 \quad 0.3881$ \\
\hline 1 pov0 & 0.3921 & 0.0000 & $0.3921 \quad 0.3921$ \\
\hline $2 p o v 0$ & 0.3943 & 0.0000 & $0.3943 \quad 0.3943$ \\
\hline \multicolumn{4}{|l|}{ Poverty gap } \\
\hline 0pov1 & 0.1311 & 0.0000 & 0.13110 .1311 \\
\hline 1 pov1 & 0.1341 & 0.0000 & $0.1341 \quad 0.1341$ \\
\hline 2 pov1 & 0.1356 & 0.0000 & $0.1356 \quad 0.1356$ \\
\hline \multicolumn{4}{|l|}{ Poverty severity } \\
\hline 0pov2 & 0.0600 & 0.0000 & $\begin{array}{ll}0.0600 & 0.0600\end{array}$ \\
\hline 1 pov2 & 0.0621 & 0.0000 & $\begin{array}{ll}0.0621 & 0.0621\end{array}$ \\
\hline 2 pov2 & 0.0632 & 0.0000 & $0.0632 \quad 0.0632$ \\
\hline \multicolumn{4}{|c|}{ Urban estimates } \\
\hline \multicolumn{4}{|c|}{ Inequality indicator } \\
\hline 0Gini & 0.3603 & 0.0061 & $\begin{array}{ll}0.3483 & 0.3722\end{array}$ \\
\hline 1Gini & 0.3615 & 0.0061 & $0.3496 \quad 0.3735$ \\
\hline 2Gini & 0.3622 & 0.0061 & $\begin{array}{ll}0.3502 & 0.3742\end{array}$ \\
\hline \multicolumn{4}{|c|}{ Poverty headcount } \\
\hline 0pov0 & 0.1836 & 0.0000 & $0.1836 \quad 0.1836$ \\
\hline 1 pov0 & 0.1868 & 0.0000 & $\begin{array}{ll}0.1868 & 0.1868\end{array}$ \\
\hline $2 p o v 0$ & 0.1890 & 0.0000 & $0.1890 \quad 0.1890$ \\
\hline \multicolumn{4}{|l|}{ Poverty gap } \\
\hline 0pov1 & 0.0476 & 0.0000 & $\begin{array}{ll}0.0476 & 0.0476\end{array}$ \\
\hline 1 pov1 & 0.0490 & 0.0000 & $\begin{array}{ll}0.0490 & 0.0490\end{array}$ \\
\hline $2 p o v 1$ & 0.0498 & 0.0000 & $\begin{array}{ll}0.0498 & 0.0498\end{array}$ \\
\hline \multicolumn{4}{|l|}{ Poverty severity } \\
\hline 0pov2 & 0.0184 & 0.0000 & $0.0184 \quad 0.0184$ \\
\hline 1pov2 & 0.0191 & 0.0000 & $0.0191 \quad 0.0191$ \\
\hline 2pov2 & 0.0195 & 0.0000 & $\begin{array}{ll}0.0195 & 0.0195\end{array}$ \\
\hline
\end{tabular}




\begin{tabular}{|c|c|c|c|}
\hline Rural estima & & & \\
\hline \multicolumn{4}{|c|}{ Inequality indicator } \\
\hline 0Gini & 0.3763 & 0.0025 & $\begin{array}{ll}0.3713 & 0.3812\end{array}$ \\
\hline 1Gini & 0.3785 & 0.0025 & $\begin{array}{ll}0.3735 & 0.3834\end{array}$ \\
\hline 2Gini & 0.3796 & 0.0025 & $\begin{array}{ll}0.3747 & 0.3845\end{array}$ \\
\hline \multicolumn{4}{|c|}{ Poverty headcount } \\
\hline Opov0 & 0.4792 & 0.0000 & $0.4792 \quad 0.4792$ \\
\hline 1 pov0 & 0.4835 & 0.0000 & $0.4835 \quad 0.4835$ \\
\hline 2 pov0 & 0.4857 & 0.0000 & $\begin{array}{ll}0.4857 & 0.4857\end{array}$ \\
\hline \multicolumn{4}{|l|}{ Poverty gap } \\
\hline 0pov1 & 0.1683 & 0.0000 & $\begin{array}{ll}0.1683 & 0.1683\end{array}$ \\
\hline 1 pov1 & 0.1720 & 0.0000 & $\begin{array}{ll}0.1720 & 0.1720\end{array}$ \\
\hline 2 pov1 & 0.1739 & 0.0000 & $\begin{array}{ll}0.1739 & 0.1739\end{array}$ \\
\hline \multicolumn{4}{|l|}{ Poverty severity } \\
\hline 0pov2 & 0.0786 & 0.0000 & $\begin{array}{ll}0.0786 & 0.0786\end{array}$ \\
\hline 1 pov2 & 0.0813 & 0.0000 & $\begin{array}{ll}0.0813 & 0.0813\end{array}$ \\
\hline 2 pov2 & 0.0826 & 0.0000 & $\begin{array}{ll}0.0827 & 0.0827\end{array}$ \\
\hline \multicolumn{4}{|c|}{ Estimates with informal sector correction } \\
\hline Variable & Mean & Std. dev. & Conf. interval \\
\hline \multicolumn{4}{|c|}{ National estimates } \\
\hline \multicolumn{4}{|c|}{ Inequality indicator } \\
\hline 0Gini & 0.3892 & 0.0028 & $0.3835 \quad 0.3949$ \\
\hline 1 Gini & 0.3901 & 0.0028 & $\begin{array}{ll}0.3845 & 0.3958\end{array}$ \\
\hline 2Gini & 0.3906 & 0.0028 & $\begin{array}{ll}0.3850 & 0.3963\end{array}$ \\
\hline \multicolumn{4}{|c|}{ Poverty headcount } \\
\hline Opov0 & 0.3881 & 0.0000 & $0.3881 \quad 0.3881$ \\
\hline 1 pov0 & 0.3903 & 0.0000 & $0.3903 \quad 0.3903$ \\
\hline 2 pov0 & 0.3915 & 0.0000 & $0.3915 \quad 0.3915$ \\
\hline \multicolumn{4}{|l|}{ Poverty gap } \\
\hline 0pov1 & 0.1311 & 0.0000 & $0.1311 \quad 0.1311$ \\
\hline 1 pov1 & 0.1323 & 0.0000 & $0.1323 \quad 0.1323$ \\
\hline 2pov1 & 0.1333 & 0.0000 & $0.1333 \quad 0.1333$ \\
\hline \multicolumn{4}{|l|}{ Poverty severity } \\
\hline 0pov2 & 0.0600 & 0.0000 & $\begin{array}{ll}0.0600 & 0.0600\end{array}$ \\
\hline 1 pov2 & 0.0609 & 0.0000 & $\begin{array}{ll}0.0609 & 0.0609\end{array}$ \\
\hline 2 pov2 & 0.0616 & 0.0000 & $\begin{array}{ll}0.0616 & 0.0616\end{array}$ \\
\hline Urban estima & & & \\
\hline
\end{tabular}




\begin{tabular}{|c|c|c|c|}
\hline \multicolumn{4}{|c|}{ Inequality indicator } \\
\hline 0Gini & 0.3603 & 0.0061 & $\begin{array}{ll}0.3483 & 0.3722\end{array}$ \\
\hline 1Gini & 0.3609 & 0.0061 & $\begin{array}{ll}0.3489 & 0.3729\end{array}$ \\
\hline 2Gini & 0.3612 & 0.0061 & $\begin{array}{ll}0.3493 & 0.3732\end{array}$ \\
\hline \multicolumn{4}{|c|}{ Poverty headcount } \\
\hline 0pov0 & 0.1836 & 0.0000 & $\begin{array}{ll}0.1836 & 0.1836\end{array}$ \\
\hline 1 pov0 & 0.1851 & 0.0000 & $\begin{array}{ll}0.1851 & 0.1851\end{array}$ \\
\hline 2 pov0 & 0.1860 & 0.0000 & $\begin{array}{ll}0.1860 & 0.1860\end{array}$ \\
\hline \multicolumn{4}{|l|}{ Poverty gap } \\
\hline 0pov1 & 0.0476 & 0.0000 & $\begin{array}{ll}0.0476 & 0.0476\end{array}$ \\
\hline 1 pov1 & 0.0483 & 0.0000 & $\begin{array}{ll}0.0483 & 0.0483\end{array}$ \\
\hline 2pov1 & 0.0487 & 0.0000 & $\begin{array}{ll}0.0487 & 0.0487\end{array}$ \\
\hline \multicolumn{4}{|l|}{ Poverty severity } \\
\hline 0pov2 & 0.0184 & 0.0000 & $\begin{array}{ll}0.0184 & 0.0184\end{array}$ \\
\hline 1pov2 & 0.0188 & 0.0000 & $\begin{array}{ll}0.0188 & 0.0188\end{array}$ \\
\hline 2pov2 & 0.0189 & 0.0000 & $\begin{array}{ll}0.0189 & 0.0189\end{array}$ \\
\hline \multicolumn{4}{|c|}{ Rural estimates } \\
\hline \multicolumn{4}{|c|}{ Inequality indicator } \\
\hline 0Gini & 0.3763 & 0.0025 & $\begin{array}{ll}0.3713 & 0.3812\end{array}$ \\
\hline 1Gini & 0.3774 & 0.0025 & $\begin{array}{ll}0.3724 & 0.3823\end{array}$ \\
\hline 2Gini & 0.3779 & 0.0025 & $\begin{array}{ll}0.3730 & 0.3829\end{array}$ \\
\hline \multicolumn{4}{|c|}{ Poverty headcount } \\
\hline Opov0 & 0.4792 & 0.0000 & $\begin{array}{ll}0.4792 & 0.4792\end{array}$ \\
\hline 1 pov0 & 0.4822 & 0.0000 & $0.4822 \quad 0.4822$ \\
\hline 2 pov0 & 0.4831 & 0.0000 & $\begin{array}{ll}0.4831 & 0.4831\end{array}$ \\
\hline \multicolumn{4}{|l|}{ Poverty gap } \\
\hline 0pov1 & 0.1683 & 0.0000 & $\begin{array}{ll}0.1683 & 0.1683\end{array}$ \\
\hline 1 pov1 & 0.1701 & 0.0000 & $\begin{array}{ll}0.1701 & 0.1701\end{array}$ \\
\hline $2 p o v 1$ & 0.1711 & 0.0000 & $\begin{array}{ll}0.1711 & 0.1711\end{array}$ \\
\hline \multicolumn{4}{|l|}{ Poverty severity } \\
\hline 0pov2 & 0.0786 & 0.0000 & $0.0786 \quad 0.0786$ \\
\hline 1 pov2 & 0.0799 & 0.0000 & $\begin{array}{ll}0.0799 & 0.0799\end{array}$ \\
\hline 2 pov2 & 0.0806 & 0.0000 & $0.0806 \quad 0.0806$ \\
\hline
\end{tabular}


Figure 2 Lorenz curves under base, pre-2011 and post-2011 PIT scenarios

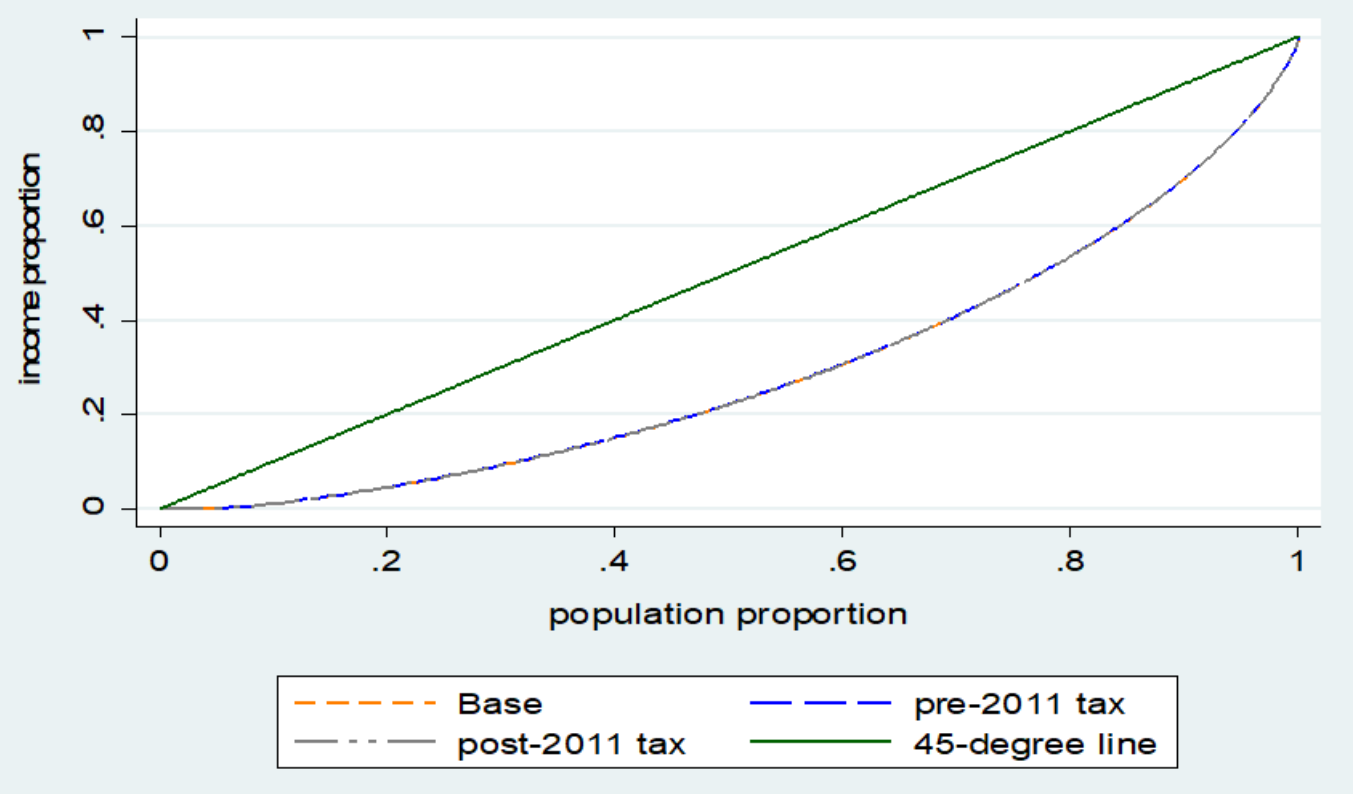

Figure 3 Lorenz curves under base, pre-2020 and post-2020 VAT scenarios

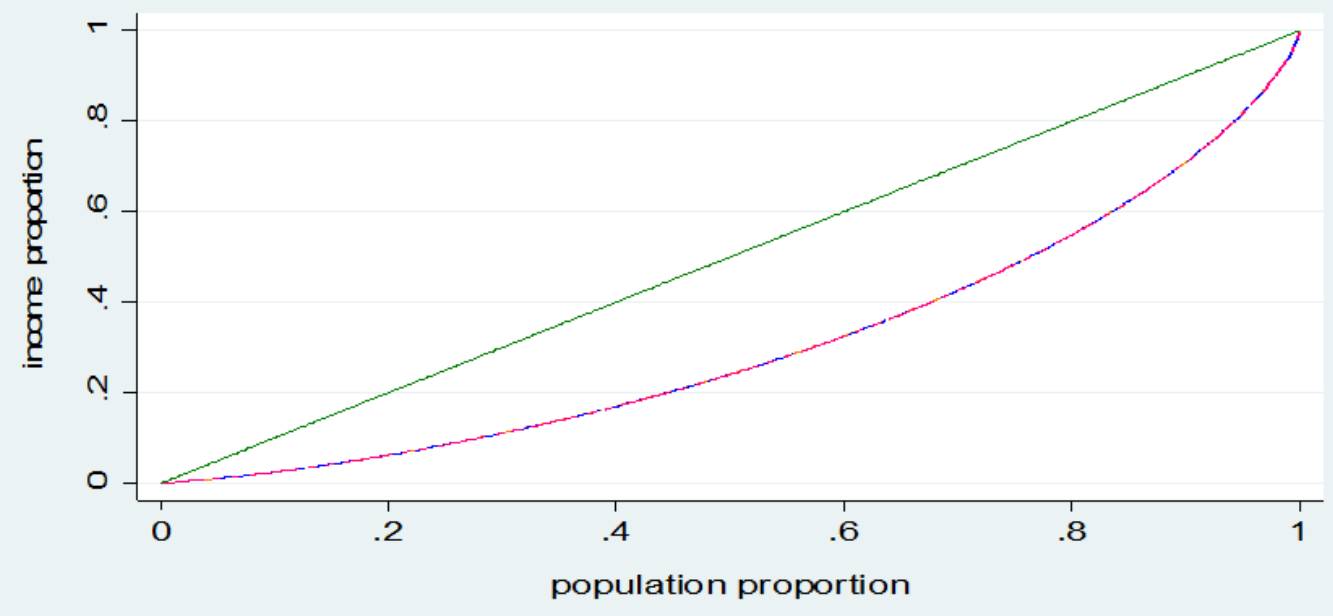

\begin{tabular}{|c|c|c|c|}
\hline $\begin{array}{l}----- \\
----\end{array}$ & $\begin{array}{l}\text { Base } \\
\text { post-2020 vat }\end{array}$ & --- & $\begin{array}{l}\text { pre-2020 vat } \\
45 \text {-degree line }\end{array}$ \\
\hline
\end{tabular}

